\title{
Nutritional Status from 1 to 15 Years and Adolescent Learning for Boys and Girls in Ethiopia, India, Peru, and Vietnam
}

\author{
Elisabetta Aurino ${ }^{1,5} \cdot$ Whitney Schott ${ }^{2}$ Jere R. Behrman ${ }^{2,3} \cdot$ Mary Penny $^{4}$
}

Received: 3 August 2018 / Accepted: 28 September 2019 / Published online: 30 October 2019

(c) The Author(s) 2019

\begin{abstract}
There has been little examination of: (1) associations of early-life nutrition and adolescent cognitive skills, (2) if they vary by gender, (3) if they differ by diverse contexts, and (4) contributions of post-infancy growth to adolescent cognitive attainment. We use Young Lives data on 7687 children from Ethiopia, India, Peru, and Vietnam to undertake ordinary least squares estimates of associations between age-1 height-for-age $z$-score (HAZ) and age-15 cognitive outcomes (math, reading, vocabulary), controlling for child and household factors. Age-1 HAZ is positively associated with cognitive scores in all countries. Child gender-specific estimates for these coefficients either do not differ (math, reading) or favor girls (vocabulary). Augmenting models to include growth in HAZ between ages 1 and 15 years that was not predicted by HAZ at age 1 reveals that such improvements are associated with higher cognitive scores, but that sex-specific coefficients for this predictor favor boys in India and Peru. The results suggest that nutritional indicators at age 1 have gender-neutral associations with math and reading and favor girls for vocabulary achievement at age 15, but unpredicted improvements in HAZ by adolescence are associated with higher cognitive scores for boys than for girls. This evidence enriches our understanding of relationships between children's nutritional trajectories during childhood and adolescent cognitive development, and how these associations vary by gender in some contexts to the possible disadvantage of girls.
\end{abstract}

Keywords Height-for-age $z$-score $(\mathrm{HAZ}) \cdot$ Life course $\cdot$ Early childhood $\cdot$ Cognitive skills $\cdot$ Gender $\cdot$ Adolescence $\cdot$ Learning $\cdot$ Ethiopia $\cdot$ India $\cdot$ Peru $\cdot$ Vietnam

Electronic supplementary material The online version of this article (https://doi.org/10.1007/s1111 3-019-09557-8) contains supplementary material, which is available to authorized users.

Elisabetta Aurino

e.aurino@imperial.ac.uk

Extended author information available on the last page of the article 


\section{Introduction}

There is a growing consensus in the early childhood development literature that experiences in very early life, from conception through early childhood, are often very formative for later outcomes. The 2017 Lancet series (Black et al. 2017) on early childhood development lays out the case for investment in early childhood development through the lens of a life course approach, recognizing that early experiences have long-term consequences on the physiological structure of the brain as well as on adult outcomes like cognition, earnings, marriage, and fertility.

Some scholars have posited early limits to critical periods of child development, suggesting that growth trajectories are irreversible after age 2 years (Victora et al. 2008) or that certain components of language learning are limited to the first 2 years of life (Friedmann and Rusou 2015; Kuhl 2010). Other studies have suggested that influences on child growth and cognition may occur through at least middle childhood. For example, data from the Young Lives study have suggested that physical growth may be responsive to socioeconomic status and other influences as late as age 8 years of age (Lundeen et al. 2014; Schott et al. 2013). Similarly, Gale et al. (2004) suggest that brain growth between infancy and 9 years of age is important in determining child cognitive skills.

More recently, scholars have made the case for focusing not just on the first 1000 days of life or mid-childhood, but the first 8000 days, including the period of adolescence as a pivotal "window of opportunity" for either remedying early nutritional deficits or forming cognitive, social emotional, executive functioning, and other skills (Bundy et al. 2017; Dahl et al. 2018; Fuhrmann et al. 2015; Steinberg 2014; Van den Berg et al. 2014). Adolescence is a distinct phase of the life course, characterized by significant physical and brain maturation and rapid development of skills related to social engagement and emotional control. The interaction of these biological processes with surrounding economic and social environments shapes human development outcomes, with lasting effects on the life course and potential repercussions on the next generation (Patton et al. 2016; Schott et al. 2017). In 2015, the estimated global population of adolescents aged between 10 and 19 years was 1.2 billion, accounting for about $16 \%$ of total world population. $90 \%$ of adolescents live in low- and middle-income countries (LMICs), whereby the barriers to achieve healthy nutrition and adequate learning outcomes, and gender equality in these goals, are often most challenging (Dahl et al. 2018). This historically unprecedented population of adolescents constitutes an opportunity for LMICs: however, in order to seize this demographic dividend, countries need to strategically invest now in adolescent health and education (Dahl et al. 2018; Patton et al. 2016).

Despite the relevance of adolescence for individual long-term outcomes and broader societal welfare, only a limited body of research has focused on this life course stage (Bundy et al. 2017). A key gap relates to the investigation of the linkages between early nutritional status and cognitive attainments in adolescence. Most studies focusing on the human development consequences of malnutrition experienced in the first 1000 days have instead focused on early and midchildhood or adulthood (see next section for a review). 
Further, evidence related to the contribution of post-infancy changes in nutritional status on human development is scarce. A limited, yet growing, literature has started to fill this gap, by focusing on the pre-pubertal and pubertal periods. These stages were identified as particularly sensitive for life course outcomes. For instance, van den Berg et al. highlighted that the period before the pubertal growth spurt constituted a critical period for adult height and other outcomes, including schooling and cognition (Van den Berg et al. 2014). Further, Akresh et al. (2017) highlighted that the long-term adverse effects on adult height were larger for children exposed to an extensive conflict-induced famine in Biafra (Nigeria) between 13 and 16 years as compared to those who were exposed at earlier ages. Second-generation effects were also found, whereby mortality and malnutrition was increased among the children of girls exposed to conflict during their adolescence.

A further research gap relates to whether the longitudinal associations between early nutritional circumstances and human development outcomes vary by gender. For instance, while Reynolds et al. (2017) examine inequalities in cognitive development by socioeconomic status, none of the previous literature has investigated gender differences in cognitive outcomes in relation to early child nutrition. This is a critical gap, since following puberty, inequalities in education by gender tend to increase (Dercon and Singh 2013). In a recent paper using Young Lives data from Ethiopia, India, Peru, and Vietnam, Singh and Krutikova (2017) found that while girls and boys tended to display similar levels of cognitive attainments prior to school entry (at 5 years) and at mid-childhood ( 8 years), wide gender inequalities were present at 19 years. Gender gaps emerged at 12 years and then widened at mid-adolescence (15 years). Similar findings were reported by Dercon and Singh (2013). Gender bias in educational attainments may be due to the increasing importance of gender norms, roles, and aspirations, which may all drive gender-specific variation in schooling participation and educational quality, time use, perceived differential returns to schooling, as well as early marriage and fertility (Alderman and King 1998; Dercon and Singh 2013; Saewyc 2017; Viner et al. 2012; Vlassoff 2007). In turn, these factors may influence the allocation of food, health, and educational expenditures towards boys. In fact, while girls tend to have better nutritional outcomes at birth than boys due to their greater biological resilience to food insecurity and other adverse circumstances (Kraemer 2000; Marcoux 2002; van den Berg et al. 2016), a pro-boy advantage in nutritional status at adolescence may stem from preferential treatment of males with regard to the intrahousehold allocation of food or health expenditures later in childhood and adolescence (Aurino 2016; Backstrand et al. 1997; Behrman 1988; Gittelsohn 1991; Hadley et al. 2008). Therefore, we hypothesize that gender differentials in growth conditional on early nutrition may be one of the factors driving inequalities in cognitive attainments by boys and girls in adolescence.

Importantly, factors underpinning gender differentials in adolescent cognitive development may be highly context-specific, and they may not always disadvantage girls. For instance, Singh and Krutikova (2017) document that while girls on average have lesser cognitive attainments in Ethiopia, India, and Peru, in Vietnam, girls outperform boys. The study of gender inequalities in attainments is important also because such disparities can also exacerbate other pre-existing inequalities (e.g., 
ethnicity, poverty, place of residence, disability) and/or future disadvantage in the labor market, potentially leading to compounding disparities over the life course.

This study aims to address these three key gaps in the literature by offering new evidence on the long-term associations between early-life nutritional indicators and learning achievements at adolescence between boys and girls, drawing on high-quality panel data from the Young Lives study. We focus specifically on gender gaps in cognitive attainments, contributing to knowledge relevant for the United Nations' Sustainable Development Goal (SDG) 4 on "quality education for all" and SDG 5 on "gender equality." While in the past two decades there has been an unprecedented increase in the share of children enrolled in primary school in LMICs, average learning levels are dismal, and gender differences tending to favor boys in cognitive attainments are widespread, particularly among the most vulnerable populations (World Bank 2018).

This paper makes five main contributions to the current body of evidence. First, by covering a span of 15 years for a recent cohort of children born in the $21^{\text {st }}$ century, it adds adolescent outcomes to a literature largely focused on the influences of early-life nutritional indicators on cognitive and other outcomes in childhood and, in a few studies, in adulthood. That there are relatively few studies on adolescent outcomes is unfortunate, since adolescence is a period during which substantial nutritional, cognitive, and non-cognitive developments occur (Bundy et al. 2017; Viner et al. 2015). Further, as adolescents were tested in multiple cognitive domains (vocabulary, maths, and reading), we are able to assess skill-based heterogeneity in the relationship between early-life height-for-age $z$-scores (HAZ) and learning achievements. Second, it compares outcomes for girls and boys during adolescence, a crucial life-cycle stage in which many gender differences become manifest, as noted above. Third, it investigates the role of changes in nutritional status between one and 15 years, thus contributing to a growing evidence base on the role of postinfancy nutrition and life course outcomes. Fourth, it presents estimates among four different LMICs representing a diversity of ethnic and cultural groups and levels of development and gender equality, rather than focusing on one country. Finally, it examines the role of age-15 school enrollment and time use as potential mediators (beyond post-infancy growth) in the relationship between early nutrition and adolescent outcomes.

\section{Early-Life Nutrition and Cognitive Attainments: Literature Review}

As noted in the introduction, there is a vast literature examining the long-term influences of early-life nutritional status and educational outcomes in childhood or, to a lesser extent, adulthood, and a remarkable paucity of evidence focusing on studying these associations in the critical adolescent life-cycle stage.

With regard to childhood outcomes, there is a large literature in economics, epidemiology, and sociology documenting associations between birthweight and anthropometric measures in infancy, and child outcomes, such as linear growth and education (Alderman et al. 2006; Aurino and Burchi 2017; Duc and Behrman 2017; Georgiadis et al. 2016; Kowalski et al. 2018; Schott et al. 2013; 
Torche and Conley 2015; Torche and Echevarría 2011). Longitudinal studies have suggested that measures of early nutritional status (height in particular) are associated with later schooling and cognitive achievement (Adair et al. 2013; Cheung and Ashorn 2010; Crookston et al. 2010, 2013; Gandhi et al. 2011; Georgiadis et al. 2016; Glewwe and King 2001; Martorell et al. 2010).

Previous research using earlier rounds of Young Lives, the same data used for this article, examines relations between HAZ at various ages with school completion and cognitive achievement. Using cognitive outcomes at age 5 years, Crookston et al. (2010) find that children who recover from early stunting have cognitive scores similar to those who are never stunted. In a follow-up paper, Crookston et al. (2013) find that HAZ is associated with higher mathematics achievement, reading comprehension, and receptive vocabulary at 8 years, and that unpredicted improvements in HAZ from ages 1 to 8 conditional on HAZ at age 1 are also associated with higher achievement for these outcomes. Georgiadis et al. (2016) propose a path model to examine pathways linking growth to cognitive development and suggest that early school enrollment may explain the link between growth trajectories and cognition at age 12 years. Kowalski et al. (2018) find that linear growth is significantly associated with math and language achievement scores at age 12 years. However, the associations are small in magnitude. Fink and Rockers (2014) examine grades completed as well as cognitive performance for verbal and math skills among the older Young Lives cohort, finding negative associations of stunting at prior ages with these outcomes.

With regard to adulthood outcomes, a body of evidence suggests a link between early-life anthropometric measures and adult outcomes, such as longterm health, cognitive skills, educational attainment, school completion, productivity, earnings, and even spousal characteristics, fertility, and anthropometrics for the next generation (Almond and Currie 2011; Behrman and Rosenzweig 2004; Hoddinott et al. 2013; Maluccio et al. 2009; Martorell et al. 2010; Nandi et al. 2018; Torche and Conley 2015). Focusing on adult educational achievements, a one-standard deviation increase in HAZ is associated with increases in schooling attainment ( 0.78 grades $)$ and higher test scores for reading and nonverbal cognitive skills ( 0.28 and $0.25 \mathrm{SDs}$, respectively) in a longitudinal sample of Guatemalan adults (Hoddinott et al. 2013; Maluccio et al. 2009). Adults born in villages involved in nutritional intervention trial villages were $9 \%$ more likely to complete secondary school and $11 \%$ more likely to complete graduate education in Andhra Pradesh, India (Nandi et al. 2018). Using data from five birth cohorts, Martorell et al. (2010) show that birthweight and weight gain in the first 2 years of life are associated with higher schooling $(0.21$ grades and 0.43 grades for birthweight and weight gain, respectively).

The remainder of this paper investigates the longitudinal associations between early childhood HAZ and adolescent learning achievements, thus bridging the gap between these two strands of literature focusing on the linkages between early-life nutrition and childhood and adulthood outcomes. 


\section{Data and Methods}

\section{Sample}

Data are from the Young Lives study, a longitudinal study of childhood poverty conducted in Ethiopia, India (Andhra Pradesh and Telangana), Peru, and Vietnam (Barnett et al. 2013). The study followed two cohorts of children in each country, totaling roughly 12,000 children, over 15 years. We focus on the Younger Cohort (about 2000 children per country), aged 6 to 18 months at study inception in 2002, because only this cohort has early-life nutritional data. These children were subsequently surveyed in 2006, 2009, 2013, and 2016, at 5, 8, 12, and 15 years of age, respectively. Within each country, children and their families were randomly selected from 20 sentinel sites. Selection from sentinel sites was by semi-purposive sampling where the site was chosen to represent the geographical, economic, social, and ethnic variation of population living in the specific area. As the Young Lives study aimed to study children at risk, poor families were oversampled. While the sample is not nationally representative (or, in the case of India, state-representative), it represents the geographic, ethnic, and socioeconomic variation of the population living in these three countries and two Indian states. Furthermore, comparison of key child outcomes or socioeconomic variables to those collected in nationally representative surveys shows similar patterns and variations (Barnett et al. 2013). Details on sample, variables construction, and other information related to the data are available at www.younglives.org.uk.

Attrition in the Young Lives study is particularly low in comparison to similar longitudinal studies, thanks to the extensive efforts made by local study teams in tracking children who moved from their original communities. Overall, only $6.8 \%$ of the initial Younger Cohort sample were not successfully re-interviewed after 15 years (Ethiopia: 9.3\%; India 5.5\%; Peru: 9.3\%; Vietnam: 3.1\%). The only round 1 predictor of tracking at 15 years is urban residence, associated with a decrease of 2 percentage points in the probability of being re-interviewed in round 5 . With this exception, no other early childhood child- or household-level characteristic is significantly associated with the probability of being part of the longitudinal sample for 15 years, which attenuates potential concerns of attrition bias. The sample sizes after attrition are Ethiopia (1813), India (1900), Peru (1860), and Vietnam (1938).

\section{Cognitive Achievements}

We focus on three main indicators of cognitive achievement at 15 years: receptive vocabulary, mathematics, and reading. Receptive vocabulary was measured with the Peabody Picture Vocabulary Test (PPVT), a measure of vocabulary development that is fairly widely administered in LMICs as well as in high-income countries. Mathematics skills were assessed through a mathematics test on topics such as basic arithmetic and short problems related to day-to-day use of math. Reading was assessed through a test with tasks ranging from matching pictures with words 
to more complex tasks, like reading short texts and responding to questions of comprehension. All tests were designed by educational experts and adapted to the formal curricula of the countries and in the local language as appropriate (Cueto et al. 2009). Cognitive tests were administered at home to include children not currently enrolled in school. About $4 \%$ of the sample $(N=323)$ is missing at least one of the three cognitive achievement tests. We age-standardize the scores within each survey round, as there is about a 12-month gap between the youngest and the oldest children in the sample children at each round. In the case of PPVT scores, we also language-standardize the scores within each major language in which the tests were taken, since psychometric properties are such that results should be compared with reference to children within the same language group (Cueto et al. 2009). Major languages are Amarigna (Amharic), Oromifa, and Tigrigna in Ethiopia; Telugu in India; Spanish in Peru, and Tiêng Việt for Vietnam. For some children, the PPVT was administered in non-major languages informally (such as translation on-thespot); these scores are excluded from our analysis due to concerns about their validity and reliability (this affects 244 children in Ethiopia and 36 children in Peru).

For each country (and in the case of PPVT, for each language), the means and standard deviations (SDs) employed in the computation of the age-standardized scores are computed using the function developed by Reynolds et al. (2017). Learning outcomes for age-in-months are estimated as a cubic polynomial (see RubioCodina et al. 2015). For the age-conditional SD, we square the residuals of the cubic polynomial regression, and then regress them on another cubic polynomial of agein-months. This method has the advantage of providing continuity in the standardized scores across months, while at the same time allowing for flexibility by month of the mean and variance used in the standardization.

\section{Early-Life Nutrition Measures}

As in most previous literature, we focus on HAZ measured at round 1 as the key marker of early-life nutritional status. In additional regressions, we also explore BMI-for-age $z$-scores (BAZ) at round 1 as an indicator of concurrent nutrition in early life. ${ }^{1}$ The use of both indicators is motivated by the fact that while HAZ captures all nutritional inputs received from conception to measurement, BAZ assesses the contemporaneous (at the time of the measurement) nutritional status of the child. Child supine length in round 1 was measured to $1 \mathrm{~mm}$ with standardized stadiometers. Weight was measured to $100 \mathrm{~g}$ using platform scales or clock balances. Two measurements were taken and the average used to increase precision. We calculate HAZ and BAZ using World Health Organization international reference standards

\footnotetext{
1 At an earlier stage, we considered the use of birthweight as an indicator of in utero health but the large proportion of missing data and self-reports, particularly for Ethiopia and, to a lesser extent, India, hampered its use. Further, a logistic regression model of missing birthweight on child and household characteristics highlighted that missing birthweight was associated with household wealth, mother's schooling, father's schooling, whether child was first-born, and household size. Given these issues, we decided to exclude birthweight from this analysis.
} 
for the relevant age groups and the children's ages in months (De Onis et al. 2004, 2007). As HAZ is inversely associated with age at recruitment given that ages ranged from 6 to 18 months, and growth faltering often occurs during this period (Victora et al. 2010), we control in all regressions for child age-in-months, age-inmonths squared, and month of birth. We generate two dichotomous indicators of early-life malnutrition, namely stunting ("low HAZ") and of "low BMI," with the cutoffs of -2 SDs from the median WHO international reference standards.

To capture childhood changes in nutritional status, we calculate the unpredicted change in HAZ from 1 to 15 as the residuals from a regression of HAZ at age 15 on HAZ at age 1 for each country separately controlling for dichotomous variables measuring child age-in-months or dummies for age-in-months squared, month and year of birth. ${ }^{2}$ This approach captures the deviations in children's HAZ trajectories from what would have been predicted based on their HAZ status at age 1. This and similar measures are increasingly used in the nutritional literature to capture change (e.g., change in HAZ) while explicitly addressing statistical issues related to highly correlated anthropometrics measurements across ages. ${ }^{3}$ The unpredicted growth in HAZ is inclusive of post-infancy growth as well as adolescent growth spurts, though the latter is not likely to be complete by age 15 for boys and for girls who started puberty when older.

\section{Other Measures}

Other measures used in the analysis are maternal height, measured at the second round of the survey using a similar method to the measurement of child height described above, but with standing height rather than supine length; completed schooling attainment for both parents, which we code to completed grades of schooling based on educational program type; urban residence; and wealth index. The wealth index (range 0-100) incorporates service access, housing quality, and asset ownership in round 1.

Child time on household tasks at age 15 is the number of hours per day typically spent on household tasks and care activities, while time in work-for-pay measures the hours per day working either for the family or an external business. ${ }^{4}$ Total time

\footnotetext{
${ }^{2}$ Some scholars advocate the use of changes in height-for-age deficits (HAD) rather than changes in HAZ to characterize changes across ages (Leroy et al. 2015). They note that HAD may increase or remain the same between two ages even if HAZ decreases, because of the increasing standard deviations of heights with age in the reference population. But using HAD implies that, say, a $10 \mathrm{~cm}$ height deficit means the same at age 15 as at age 1, which we find questionable. Instead we think that measuring height relative to the reference distributions with their age-dependent standard deviations and medians is more plausible. Therefore, we follow the dominant convention in the literature and use HAZ changes across ages, and not HAD changes across ages.

3 A similar approach was adopted in Martorell et al. (2010).

4 We considered merging work within and outside the household into a single category, but given the gendered division of work (with girls contributing more to household tasks and boys more engaged in paid work), we think that leaving them separate improves understanding of underlying mechanisms, with a specific emphasis on gender. This measure is also consistent with the ILO definition of child labor, which only considers time in industry/services business or agriculture as forms of child labor (see https:// www.ilo.org/ipec/facts/lang--en/index.htm).
} 
in educational activities measures the number of hours per day a 15-year-old spent either in school or studying. School enrollment at age 15 reflects whether an adolescent was enrolled in school at the time of the survey. We also create a variable labeled "early puberty" that indicates whether respondents answered that they had started menstruation in the case of girls, or had hair on their chin or experienced voice changes for boys, at round 4 (12 years).

\section{Statistical Methods}

To address missing values, we conduct multiple imputation using chained equations (White et al. 2011) through the command ice in Stata 15.1 with the option of 25 imputations. While this procedure does not address potential selection bias due to missing values that are not random, it presents efficiency advantages compared to other missing data imputation techniques, such as unconditional mean imputation, as it exploits fully the variation in the data. Although we compute the multiple imputation for all the independent and dependent variables, we restrict the models to those observations for which the cognitive scores, our main outcomes, are not missing. ${ }^{5}$ Descriptive statistics were computed before the multiple imputation.

For the main analysis, we conduct ordinary least squares regressions of the three cognitive scores (PPVT, mathematics, reading) at age 15 years on HAZ at age 1 year and a series of controls, including a dummy indicating the child is male, age-inmonths, age-in-months squared, month of birth, maternal height, mother's completed grades of schooling, father's completed grades of schooling, wealth index, household size, and a dummy for urban residence. We also include interactions of all the regressors with the male child dummy to examine differences in the coefficient estimates of these predictors by child gender. All included controls were measured at round 1 when the child was age $\sim 1$ year, except for maternal height and parental schooling, which were collected in round 2 when the child was age 5 years. We run separate estimates for each country, as Chow-Rao tests of equality of coefficients showed that there were differences in the associations of HAZ and its interaction with gender with test scores across countries, which implied that pooling the countries together may mask important heterogeneities in these relationships.

We then add to the main model by examining potential mediators through which the impacts of early-life nutritional status on learning by adolescence may occur in each country setting. We examine how the coefficient estimates for the early-life HAZ in the main model change when specifications also include: (i) school enrollment, (ii) time use (time in household tasks, time in work outside the household; time in education), and (iii) unpredicted changes in HAZ from age 1 to 15. As per the main model, we include interactions with child gender in each of these augmented models.

Finally, as a supplementary analysis, we include, in two different models: (iv) unpredicted changes in HAZ from 1 to 8 years and (v) early puberty as a channel on

\footnotetext{
5 It is standard practice to only include non-missing dependent variable values when using multiple imputation (White et al. 2011).
} 
its own, and the interactions of these variables with child gender. Puberty represents a time of great biological and psychological change that is unobserved directly in the data, yet possibly crucial to learning attainments and differences between boys and girls in those outcomes. For instance, there may be unobserved systematic variation based on pubertal development in terms of biological (e.g., brain development, hormonal changes) or social factors (e.g., norms, increased absenteeism due to menstruation). Similarly, by including unpredicted HAZ by age 8 years (prior to the pubertal growth spurt), we investigate whether the associations between unpredicted growth after age 1 and adolescent cognitive attainments are similar regardless of whether we consider the pubertal period or not in the estimation of childhood growth trajectories.

Given that Young Lives sampling was undertaken by choosing 20 sentinel sites in each country, we cluster the standard errors at the sentinel site at round 1 in all models to adjust for clustering of children residing in the same sentinel site.

\section{Compliance with Ethical Standards}

During data collection, all procedures performed with human subjects were in accordance with the ethical standards of the institutional and/or national research committee and with the 1964 Helsinki declaration and its later amendments or comparable ethical standards. Informed consent was obtained from all individual participants (children, caregivers, and any other involved) at each round of fieldwork (Morrow 2013). Young Lives has received approval from the ethical board of the University of Oxford and the study countries. The authors declare no conflicts of interest.

\section{Results}

\section{Descriptive Statistics}

Table 1 presents descriptive statistics of early childhood nutritional indicators and cognitive outcomes (excluding missing values prior to multiple imputation), with gender differences by country. Malnutrition at age 1 year was prevalent: $31 \%$ of children were stunted and $11 \%$ had low BMI. Levels of malnutrition varied across countries: Ethiopia had the largest burden of stunting and low BMI, while Vietnam had the lowest prevalence of both. Girls had higher age-1-year HAZ and BAZ scores than boys, and, consequently, lower prevalence of stunting and low BMI in all four countries, which is consistent with the literature on gender disparities in early nutrition reviewed in the introduction.

The sample countries are also very different in terms of gender disparities in adolescent cognitive attainments. In Ethiopia, there were no gender differences across the three cognitive skills, while in India and Peru, adolescent girls had lower scores 
Table 1 Descriptive statistics, by gender and country

\begin{tabular}{|c|c|c|c|c|c|}
\hline & \multicolumn{2}{|c|}{ Girls } & \multicolumn{2}{|l|}{ Boys } & \multirow[t]{2}{*}{ Diff. (girls-boys) } \\
\hline & $N$ & Mean $[\mathrm{SE}]$ & $N$ & Mean $[\mathrm{SE}]$ & \\
\hline \multicolumn{6}{|l|}{ Ethiopia } \\
\hline \multicolumn{6}{|c|}{ Nutrition indicators at 1 year (2002) } \\
\hline HAZ & 727 & $-1.552[0.060]$ & 808 & $-1.875[0.055]$ & $0.323^{\dagger}$ \\
\hline BAZ & 722 & $-1.25[0.063]$ & 803 & $-1.441[0.060]$ & $0.191 *$ \\
\hline Stunted & 727 & $0.414[0.018]$ & 808 & $0.5[0.018]$ & $-0.086^{\dagger}$ \\
\hline Low BMI & 787 & $0.156[0.013]$ & 883 & $0.179[0.013]$ & -0.023 \\
\hline \multicolumn{6}{|c|}{ Learning achievements at 15 years (2016) } \\
\hline Math & 807 & $-0.458[0.028]$ & 901 & $-0.429[0.025]$ & -0.029 \\
\hline PPVT & 754 & $-0.028[0.038]$ & 848 & $0.023[0.033]$ & -0.051 \\
\hline Reading & 795 & $-0.095[0.041]$ & 882 & $-0.163[0.038]$ & 0.068 \\
\hline \multicolumn{6}{|l|}{ India } \\
\hline \multicolumn{6}{|c|}{ Nutrition indicators at 1 year (2002) } \\
\hline HAZ & 838 & $-1.164[0.047]$ & 976 & $-1.345[0.047]$ & $0.180^{\dagger}$ \\
\hline BAZ & 838 & $-1.118[0.045]$ & 979 & $-1.281[0.046]$ & $0.163^{*}$ \\
\hline Stunted & 838 & $0.271[0.015]$ & 976 & $0.316[0.015]$ & $-0.045^{*}$ \\
\hline Low BMI & 848 & $0.168[0.013]$ & 991 & $0.221[0.013]$ & $-0.054^{\dagger}$ \\
\hline \multicolumn{6}{|c|}{ Learning achievements at 15 years (2016) } \\
\hline Math & 844 & $-0.283[0.029]$ & 992 & $-0.132[0.029]$ & $-0.150^{\dagger}$ \\
\hline PPVT & 868 & $-0.068[0.038]$ & 1018 & $0.058[0.028]$ & $-0.126^{\dagger}$ \\
\hline Reading & 838 & $-0.156[0.030]$ & 989 & $-0.224[0.028]$ & 0.067 \\
\hline \multicolumn{6}{|l|}{ Peru } \\
\hline \multicolumn{6}{|c|}{ Nutrition indicators at 1 year (2002) } \\
\hline HAZ & 885 & $-1.233[0.039]$ & 898 & $-1.406[0.042]$ & $0.173^{\dagger}$ \\
\hline BAZ & 883 & $-0.692[0.050]$ & 897 & $-0.873[0.052]$ & $0.182 * *$ \\
\hline Stunted & 885 & $0.25[0.015]$ & 898 & $0.311[0.015]$ & $-0.061^{\dagger}$ \\
\hline Low BMI & 902 & $0.021[0.005]$ & 913 & $0.022[0.005]$ & -0.001 \\
\hline \multicolumn{6}{|c|}{ Learning achievements at 15 years (2016) } \\
\hline Math & 922 & $0.069[0.030]$ & 938 & $0.242[0.032]$ & $-0.173^{\dagger}$ \\
\hline PPVT & 894 & $-0.088[0.033]$ & 917 & $0.086[0.033]$ & $-0.175^{\dagger}$ \\
\hline Reading & 896 & $0.443[0.027]$ & 910 & $0.448[0.027]$ & -0.005 \\
\hline \multicolumn{6}{|l|}{ Vietnam } \\
\hline \multicolumn{6}{|c|}{ Nutrition indicators at 1 year (2002) } \\
\hline HAZ & 908 & $-1.023[0.036]$ & 944 & $-1.203[0.038]$ & $0.180^{\dagger}$ \\
\hline BAZ & 909 & $-0.834[0.037]$ & 945 & $-0.937[0.039]$ & $0.103^{*}$ \\
\hline Stunted & 908 & $0.176[0.013]$ & 944 & $0.244[0.014]$ & $-0.067^{\dagger}$ \\
\hline Low BMI & 910 & $0.035[0.006]$ & 949 & $0.046[0.007]$ & -0.011 \\
\hline \multicolumn{6}{|c|}{ Learning achievements at 15 years (2016) } \\
\hline Math & 925 & $0.531[0.037]$ & 963 & $0.357[0.035]$ & $0.174^{\dagger}$ \\
\hline PPVT & 944 & $0.012[0.033]$ & 987 & $-0.012[0.031]$ & 0.024 \\
\hline Reading & 929 & $0.052[0.033]$ & 963 & $-0.291[0.032]$ & $0.343^{\dagger}$ \\
\hline
\end{tabular}

Descriptive statistics are computed prior to multiple imputation. Stunting is an indicator of chronic malnutrition, and assumes the value of 1 when HAZ is below -2 SDs from the international reference standard (De Onis et al. 2004). Low BMI assumes the value of 1 if BAZ is below -2 SDs from the interna- 
Table 1 (continued)

tional reference standard (de Onis et al. 2004). The values displayed for the difference are the differences in the means between girls and boys with $t$ tests for significance. All tests are age-standardized; PPVT is also standardized within each main language

$\dagger$ and $*$ indicate significance at the 1 and 5 percent critical levels

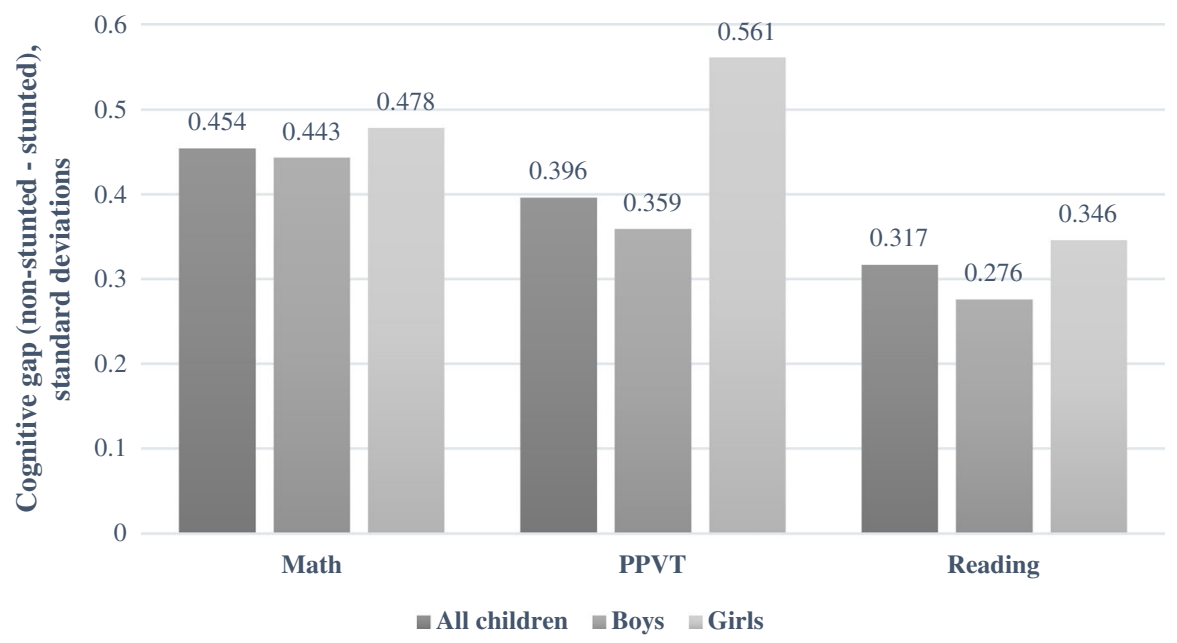

Fig. 1 Adolescent mean cognitive achievement inequalities by stunting at 1 year, full sample and by child gender. Notes: This figure presents mean cognitive achievements at 15 years by stunting status at Round 1, for the full sample and by child gender. Each bar provides the difference between the mean test scores between non-stunted children and stunted children. All differences are statistically significant at the $1 \%$ level. All tests are age-standardized, and PPVT is also standardized within each main language. Stunting is an indicator of chronic malnutrition, and assumes the value of 1 when HAZ is 2 SDs or more below the international reference standard

than their male counterparts for math and PPVT. In contrast, adolescent girls in Vietnam performed better than boys in math and reading.

Figure 1 shows mean adolescent cognitive gaps at age 15 years by stunting status at age 1 year, between boys and girls as a general overview of gender differences in test scores for the pooled sample. At a descriptive level, there was a large gap in cognitive achievements at mid-adolescence by age 1 stunting. The average gaps in mean test scores for the full sample were $0.45 \mathrm{SD}$ in math, 0.40 SD in vocabulary, and $0.32 \mathrm{SD}$ in reading. When stratified further by gender, girls who were stunted at age 1 year had larger gaps than boys who were stunted at the same age, particularly for PPVT.

Beyond this general picture, Fig. 2a-c explores differences by gender in adolescent achievements by plotting the entire distribution of test scores by age $1 \mathrm{HAZ}$ for each country. Figure 2 a presents gender differences for math. In India, and to a lesser extent in Peru, the distribution of math achievements for girls tended to lie 
below the one for boys across the whole distribution of age-1 HAZ. By contrast, in Ethiopia and Vietnam, girls at the bottom of the HAZ distribution tended to outperform boys in math, though for higher levels of HAZ, boys were more likely to fare better than girls. For PPVT, as for math, girls tended to fall behind boys across the whole distribution in India and Peru, although the magnitude of the gender gap was generally less pronounced than for math (Fig. 2b). No remarkable differences were evident for Vietnam and for Ethiopia. Finally, for reading, Fig. 2c shows that in Vietnam and Ethiopia, girls tended to outperform boys for most of the distribution of HAZ (in Vietnam across the whole distribution), while there was no clear pattern for India and Peru.

\section{Main Results}

Table 2 presents results from the main model that regresses cognitive scores at age 15 years on age- $1 \mathrm{HAZ}$ and includes interactions with the male child dummy. The coefficient for age-1 HAZ indicates significant associations with cognitive performance in math, vocabulary, and reading. Estimates suggest that a one unit increase in HAZ is associated significantly with 0.05 and 0.07 increases in SD units for math in India and Peru, 0.09-0.14 increases for PPVT across all countries, and a 0.09 increase for reading in India. Estimates are equivalent for adolescent boys and girls for math and reading, but not for PPVT. Adolescent girls with higher values of age-1 HAZ are at an advantage for PPVT relative to boys in all countries except Peru. This advantage is particularly pronounced for girls in India (the coefficient estimate for the interaction term, providing the association of HAZ for males, is -0.095 , implying that a one unit higher HAZ is associated with only 0.005 increase in PPVT scores for boys).

In an extension, we augment the main model with BAZ at age 1 and its interaction with gender to investigate whether the inclusion of this indicator of concurrent malnutrition at age 1 predicts adolescent test scores over and beyond HAZ. Results are in Supplementary Materials 1. The inclusion of BAZ does not change the size or statistical significance of HAZ, nor of its interaction with child gender. BAZ is only significantly associated (at $10 \%$ level) with reading scores in India. The interaction between gender and BAZ is also only positively associated with higher PPVT scores for boys in India.

\section{Extension: Are Gaps in Adolescent Cognitive Attainments Mediated by Schooling, Time Use, and Post-infancy Growth?}

We augment the main model presented in Table 2 to examine whether coefficients on HAZ are robust to the inclusion of additional predictors, possibly mediators, of adolescent cognitive performance. In models 1-3 included in Tables 3, 4, and 5, separately for each country, we include, respectively, (1) school enrollment, (2) time use, and (3) unpredicted changes in HAZ from ages 1 to 15 years. We explore the inclusion of school enrollment and time use, as these characteristics might be key predictors of cognitive scores at adolescence, potentially mediating and therefore 
Fig. 2 a Adolescent math achievements distribution by HAZ at 1 year, by child gender and country. Notes: This figure presents mean math achievements at 15 years by HAZ at Round 1, by child gender and country. b Adolescent vocabulary achievements distribution by HAZ at 1 year, by child gender and country. Notes: This figure presents mean vocabulary achievements at 15 years by HAZ at Round 1 , by child gender and country. Vocabulary is measured by the PPVT test. c Adolescent reading achievements distribution by HAZ at 1 year, by child gender and country. Notes: This figure presents mean reading achievements at 15 years by HAZ at Round 1 , by child gender and country

attenuating the coefficient estimates for the regressors estimated in the main model. The inclusion of unpredicted changes in HAZ tests whether changes in HAZ after age-1 year are separate predictors of cognitive scores. If these additional factors explain some of the variation in adolescent cognitive attainment, the size and statistical magnitude of the coefficient estimates associated with early-life nutrition may be reduced. Each of these variables are, again, interacted with being male, to investigate sex-specific patterns. Tables 3, 4, and 5 report the results for math, PPVT, and reading, respectively. When significant in the main model reported in Table 2, the coefficients on HAZ do not attenuate in these extended models. In the model controlling for schooling, enrolment is associated with higher math, PPVT, and reading scores for adolescent girls and boys. Time use is differentially associated with scores across countries and for boys versus girls (model 2). Every additional hour spent on household tasks is inversely associated with math and reading scores in Vietnam, and with vocabulary in India. Examining the interactions with the male dummy, hours spent on household tasks are associated with lower math scores for boys compared to girls in Ethiopia and Peru, and with lower reading scores for boys in Ethiopia. Hours spent in work activities outside the household are positively associated with math and inversely associated with vocabulary in Ethiopia. In Peru, hours of work are negatively associated with math scores. When significant, the interaction between time spent in work outside the household and being male shows that, as compared to girls, boys have higher test scores holding hours of work constant. The only exception is for Ethiopia in the case of math, where time spent in work is associated with higher achievements for girls as compared to their male counterparts. Hours spent in school or studying are associated with higher cognitive scores for all three outcomes and across all countries. Unpredicted post-infancy height growth (model 3) is associated with improvements in test scores in the countries that have higher prevalence of early malnutrition (Ethiopia and India) for math and reading, with magnitudes ranging between 0.08SD and 0.10SD. Also, the associations between unpredicted changes in HAZ for all outcomes favor boys' cognitive scores in India and Peru. For instance, in India, one SD increase in unpredicted changes in HAZ is positively associated with an increase of more than 0.02SD units of PPVT for boys. Similarly, in Peru, post-infancy growth is only associated with higher boys' test scores in math and PPVT, and in India the association is only manifest for boys' reading scores.

In separate analyses presented in Supplementary Tables S2.A, S2.B, and S2.C for math, PPVT, and reading, respectively, we examine whether the relationships observed in the model controlling for unpredicted growth between 1 and 15 years occurred prior to the pubertal growth spurt, by age 8 years (round 3), or whether 

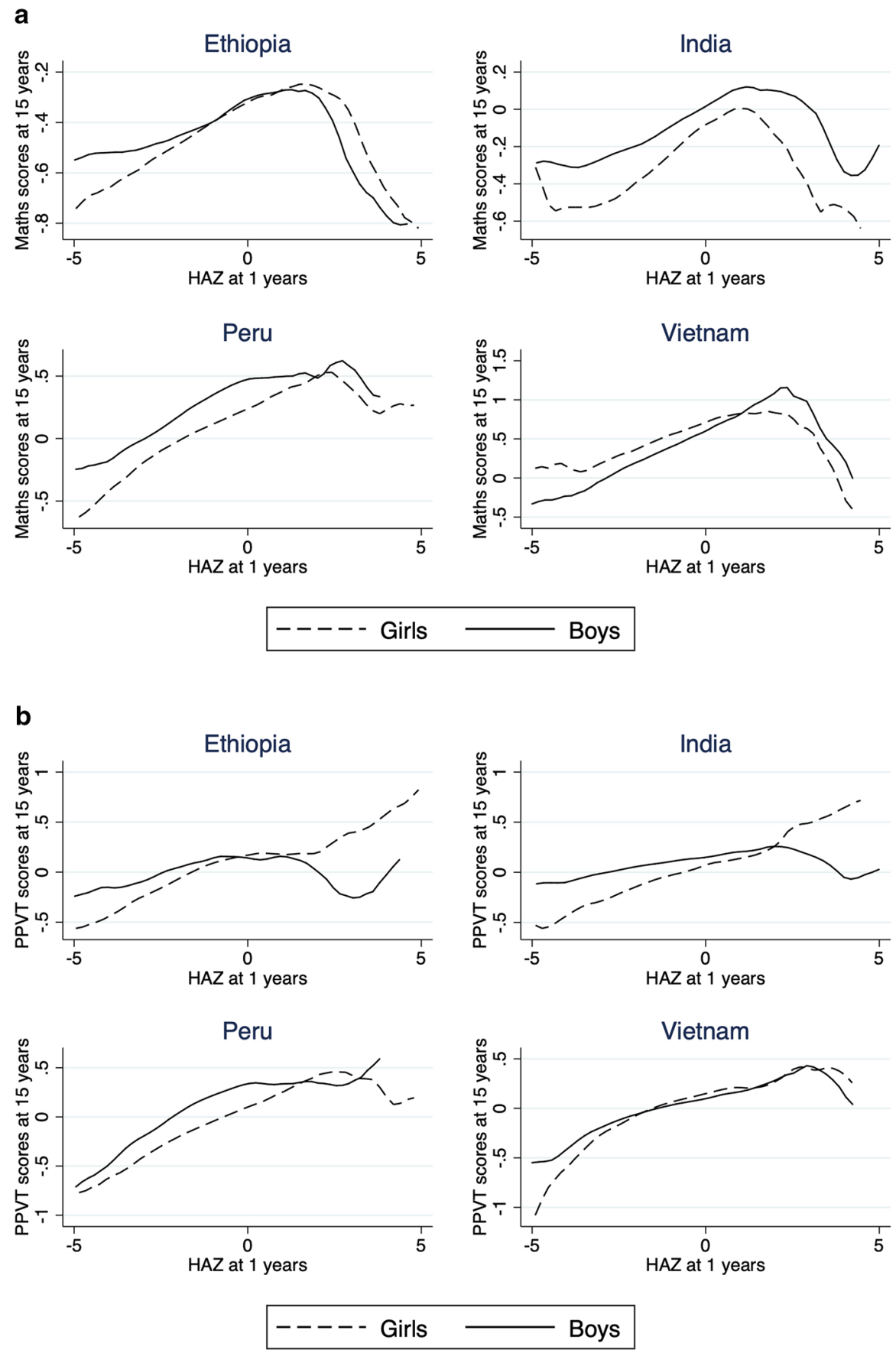

associations are similar regardless of the period of time of unpredicted growth considered. These estimates highlight that the associations between unpredicted change 

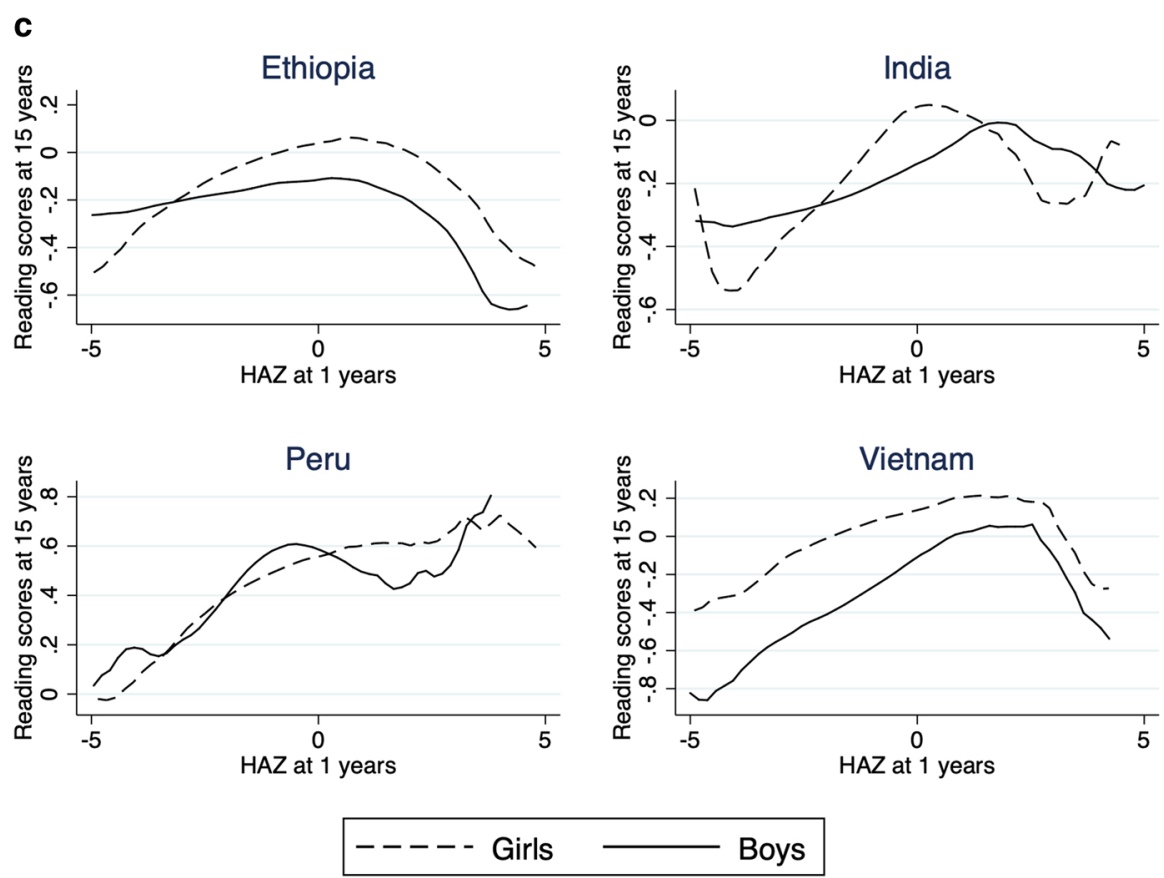

Fig. 2 (continued)

in HAZ between ages 1 and 8 are about the same magnitude as those reported in Tables 3 and 5 for Ethiopia and India. In India, the male advantage in unpredicted change in HAZ for PPVT is smaller at 8 years than at 15 years, while in Vietnam we find some male advantage of unpredicted growth for vocabulary that then disappears at 15 years. Finally, in the same Supplementary Tables, we examine a fifth model including an indicator of early puberty and its interaction with gender. In this set of estimates, we find that adolescents who entered puberty early had higher scores for math and reading in Peru (girls in particular), and for PPVT in India (Table S2.B).

\section{Discussion and Conclusions}

This paper provides several contributions to the child and adolescent development literatures. First, it is the only paper of which we are aware that examines associations between early-life nutritional status and multiple adolescent cognitive outcomes using comparative longitudinal data from several LMICs. Second, we assess the predictive role of early-life nutrition on learning attainments by gender. Third, we provide new evidence on the timing of the contribution of physical growth to the divergence of cognitive outcomes, as well as heterogeneity in this association by gender.

We document six main findings: first, at a descriptive level, at age 1 year, girls on average have better nutritional status than boys in the four countries studied, which 
Table 2 Regressions of math, PPVT, and reading scores on HAZ

\begin{tabular}{|c|c|c|c|c|}
\hline & Ethiopia & India & Peru & Vietnam \\
\hline \multicolumn{5}{|l|}{ Math } \\
\hline Male & $\begin{array}{l}-0.133 \\
(0.124)\end{array}$ & $\begin{array}{l}0.140 \\
(0.151)\end{array}$ & $\begin{array}{l}0.149 \\
(0.186)\end{array}$ & $\begin{array}{l}-0.189 \\
(0.208)\end{array}$ \\
\hline $\mathrm{HAZ}$ at age 1 year & $\begin{array}{l}0.022 \\
(0.024)\end{array}$ & $\begin{array}{l}0.049 * \\
(0.026)\end{array}$ & $\begin{array}{l}0.065 * * \\
(0.024)\end{array}$ & $\begin{array}{l}0.055 \\
(0.033)\end{array}$ \\
\hline HAZ $\times$ male & $\begin{array}{l}-0.002 \\
(0.021)\end{array}$ & $\begin{array}{l}-0.012 \\
(0.030)\end{array}$ & $\begin{array}{l}-0.026 \\
(0.037)\end{array}$ & $\begin{array}{l}0.061 \\
(0.040)\end{array}$ \\
\hline Observations & 1554 & 1795 & 1752 & 1857 \\
\hline \multicolumn{5}{|l|}{ PPVT } \\
\hline Male & $\begin{array}{l}0.187 \\
(0.189)\end{array}$ & $\begin{array}{l}0.266 \\
(0.213)\end{array}$ & $\begin{array}{l}0.145 \\
(0.171)\end{array}$ & $\begin{array}{l}-0.256 \\
(0.171)\end{array}$ \\
\hline $\mathrm{HAZ}$ at age 1 year & $\begin{array}{l}0.092 * * * \\
(0.028)\end{array}$ & $\begin{array}{l}0.142 * * * \\
(0.022)\end{array}$ & $\begin{array}{l}0.086 * * \\
(0.034)\end{array}$ & $\begin{array}{l}0.127 * * * \\
(0.041)\end{array}$ \\
\hline HAZ $\times$ male & $\begin{array}{l}-0.078 * * \\
(0.029)\end{array}$ & $\begin{array}{l}-0.095 * * * \\
(0.026)\end{array}$ & $\begin{array}{l}-0.024 \\
(0.034)\end{array}$ & $\begin{array}{l}-0.066^{*} \\
(0.037)\end{array}$ \\
\hline Observations & 1,448 & 1,844 & 1,706 & 1,899 \\
\hline \multicolumn{5}{|l|}{ Reading } \\
\hline Male & $\begin{array}{l}-0.264 * \\
(0.146)\end{array}$ & $\begin{array}{l}-0.020 \\
(0.169)\end{array}$ & $\begin{array}{l}0.109 \\
(0.156)\end{array}$ & $\begin{array}{l}-0.676^{* * * *} \\
(0.206)\end{array}$ \\
\hline HAZ at age 1 year & $\begin{array}{l}0.027 \\
(0.032)\end{array}$ & $\begin{array}{l}0.085 * * \\
(0.033)\end{array}$ & $\begin{array}{l}0.012 \\
(0.031)\end{array}$ & $\begin{array}{l}0.042 \\
(0.034)\end{array}$ \\
\hline $\mathrm{HAZ} \times$ male & $\begin{array}{l}-0.047 \\
(0.034)\end{array}$ & $\begin{array}{l}-0.049 \\
(0.038)\end{array}$ & $\begin{array}{l}0.020 \\
(0.033)\end{array}$ & $\begin{array}{l}0.008 \\
(0.045)\end{array}$ \\
\hline Observations & 1,523 & 1,704 & 1,860 & 1,860 \\
\hline
\end{tabular}

OLS regressions also include child age-in-months dummies; age-inmonths squared dummies, month of birth, first-born, household size and urban residence at age 1, maternal height, parental schooling attainment, and each of these variables interacted with male child. Standard errors clustered at sentinel site level in parentheses

$* p<0.1 ; * * p<0.05 ; * * * p<0.01$

is consistent with a literature showing that boys' nutrition in the early years is more vulnerable to food insecurity than girls' (Kraemer 2000; Marcoux 2002; van den Berg et al. 2016). However, by age 15 years boys have higher cognitive scores than girls in two of the four countries (India and Peru), while girls have a cognitive advantage over boys in one country (Vietnam). There are no gender differences in cognitive performance at age 15 years in Ethiopia. This finding contrasts with a body of literature reporting that unit increases in early-life HAZ are associated with subsequent improved cognition (see "Literature review" section, and for a meta-analysis of prospective studies focusing on cognition of children aged 5-11 years, see Sudfeld et al. 2015). Based on this literature, in our sample we would have expected better cognitive performance among adolescent girls, as they had higher early-life nutrition in all countries. Second, after controlling for several child and household 


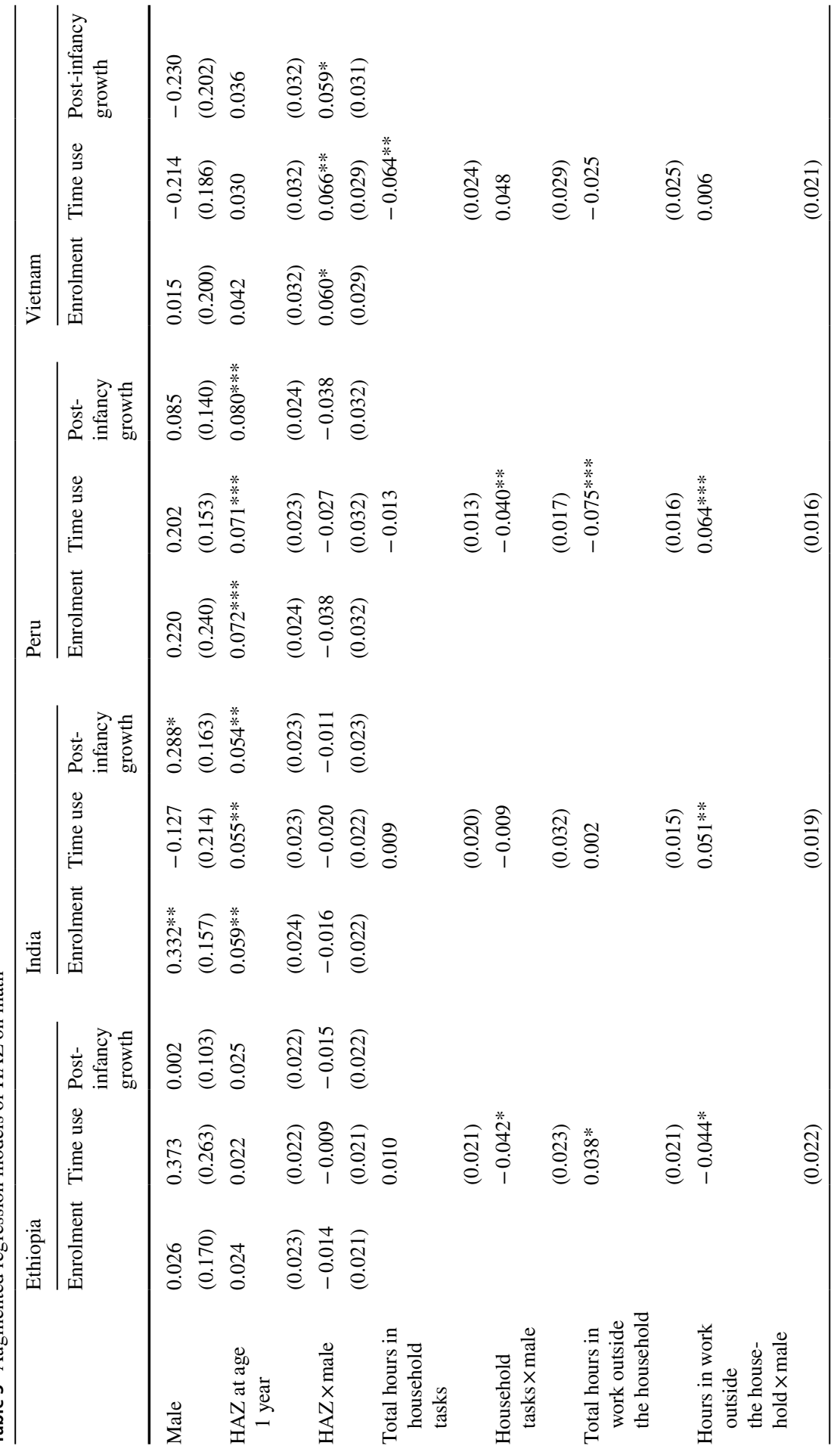




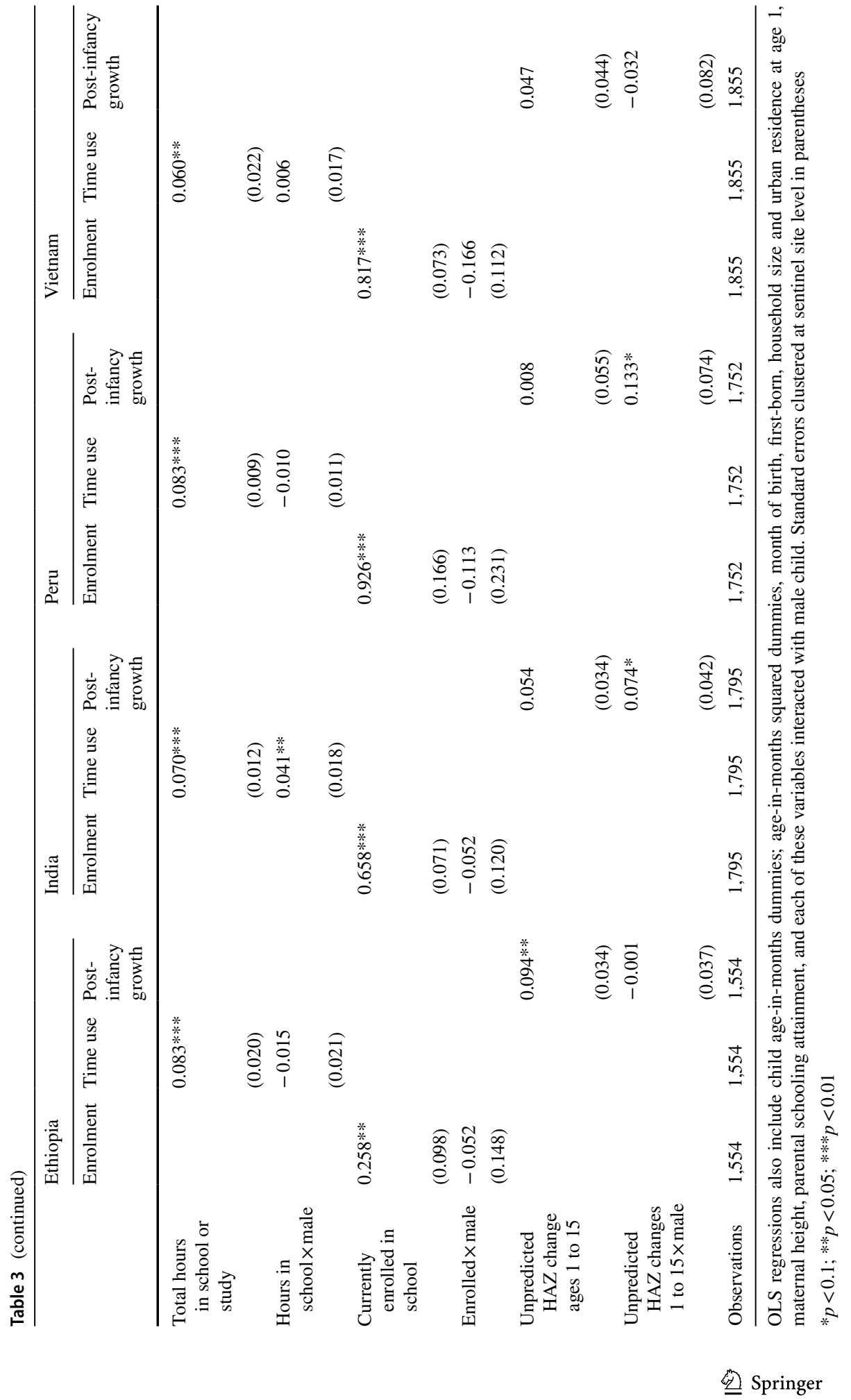




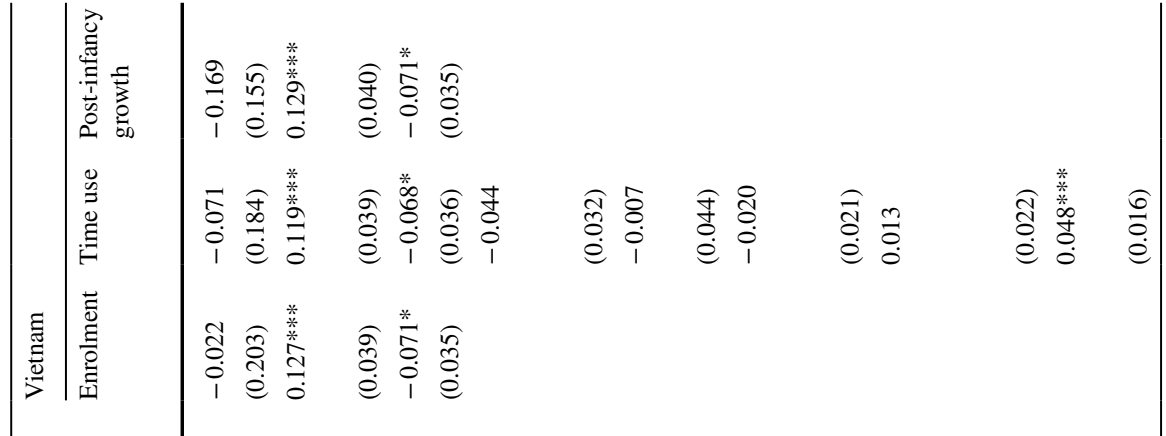

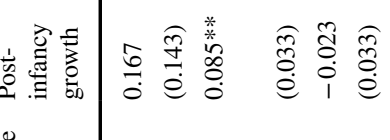

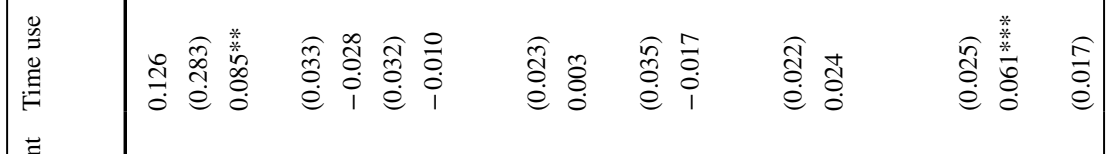

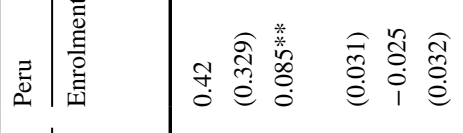

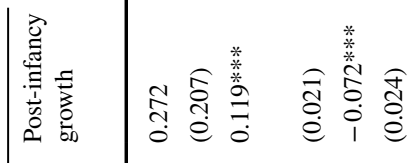

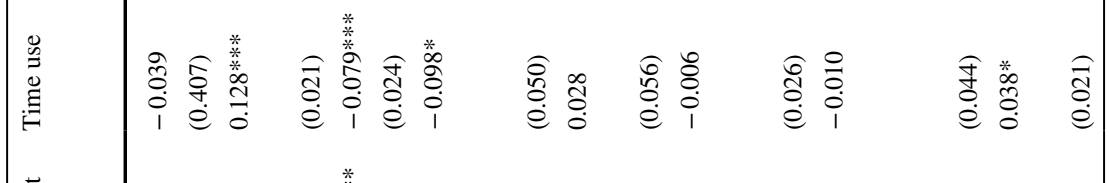

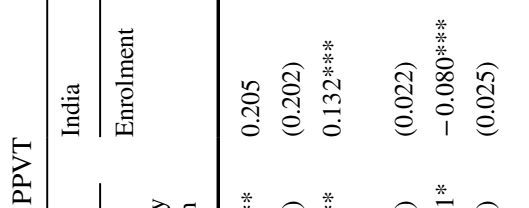

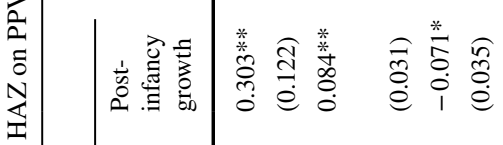

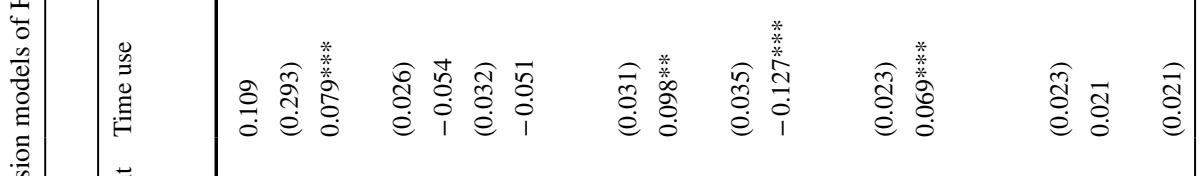

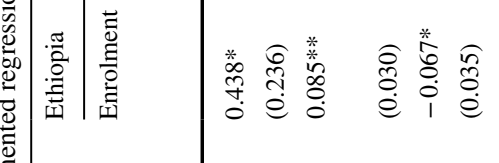

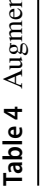

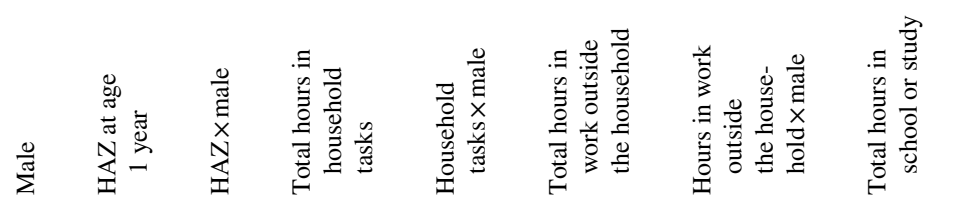




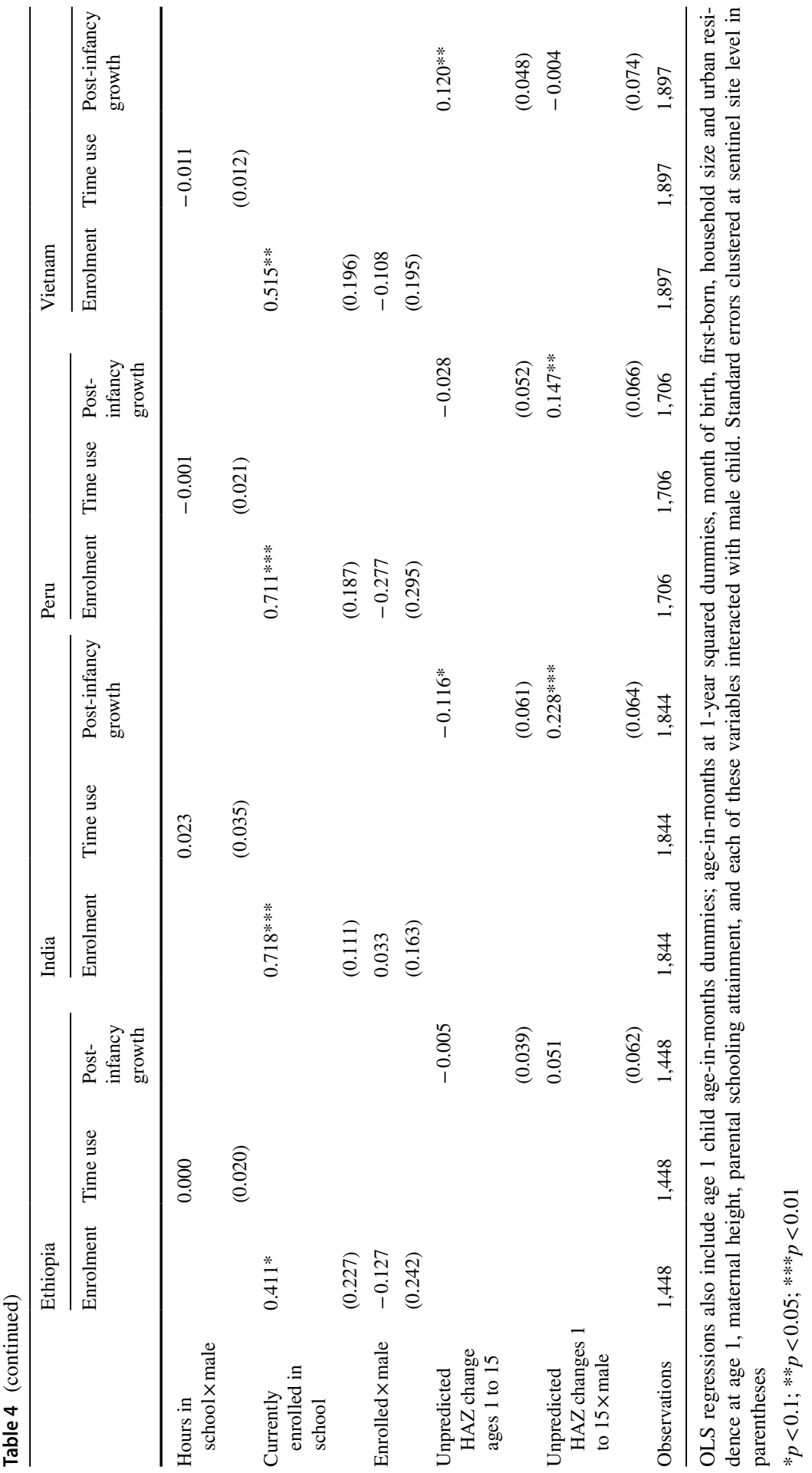




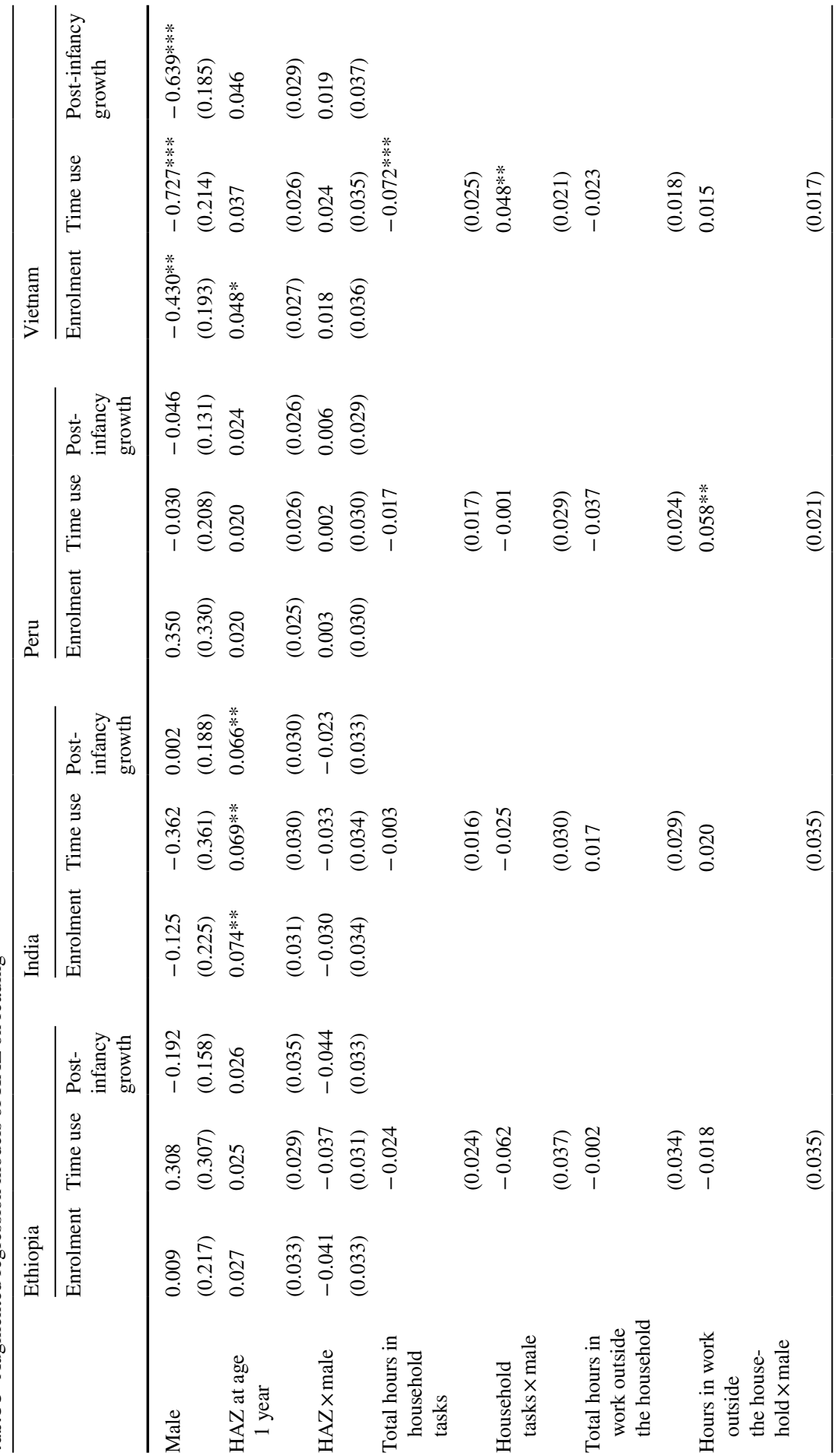




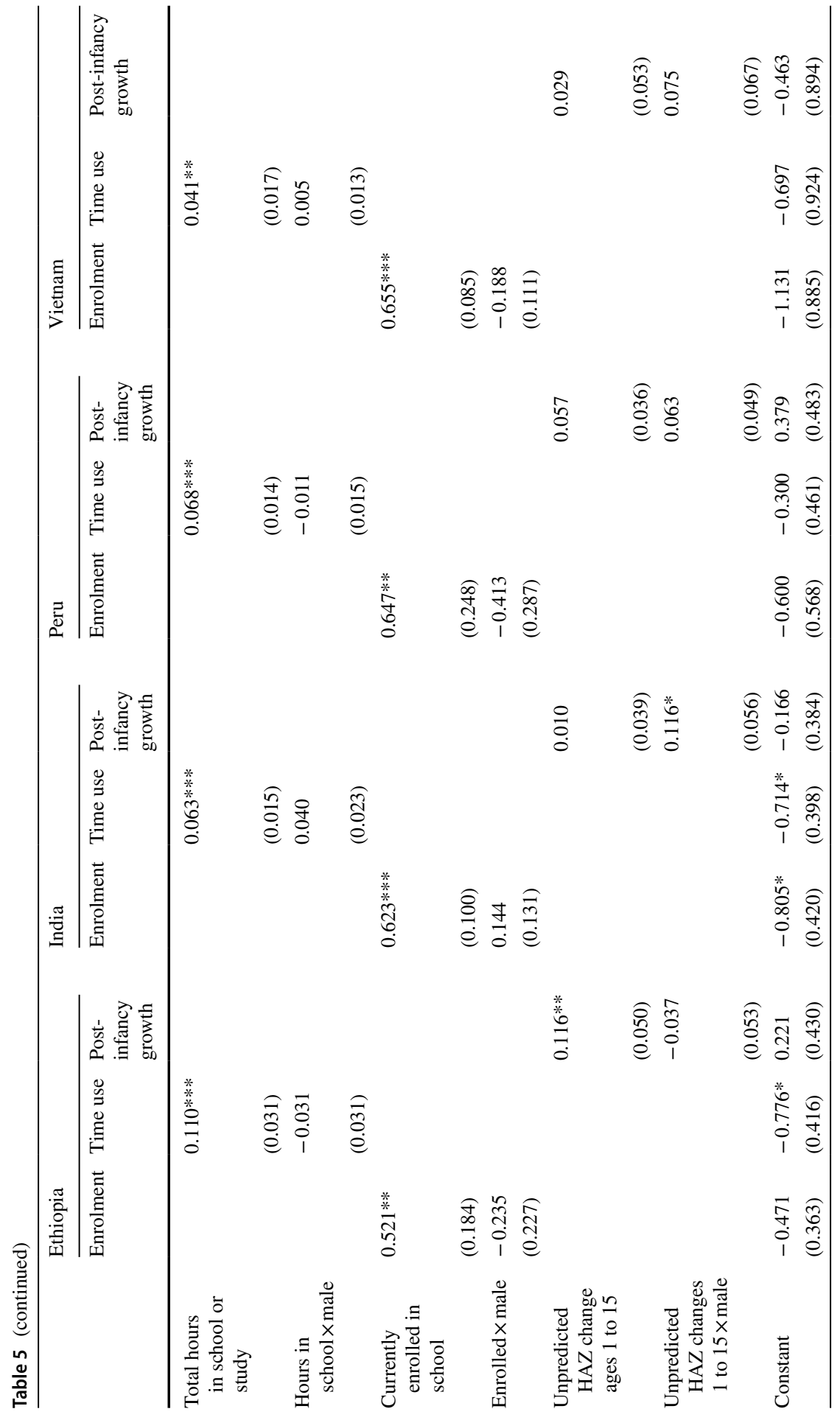




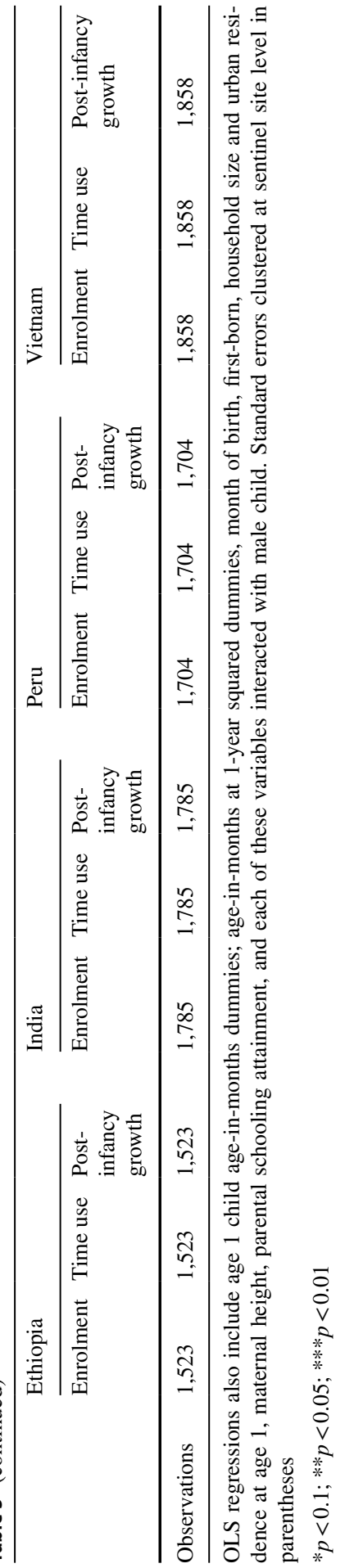


characteristics using ordinary least squares multivariate regressions, early-life nutritional indicators (HAZ and, to a lesser extent, BAZ at age 1 year) predict higher cognitive scores at age 15 years in all countries, which is consistent with previous literature. Third, there is heterogeneity in the associations between HAZ and specific skills across countries: HAZ consistently predicts significantly higher PPVT scores in all study settings, but only significantly predicts higher math scores in India and Peru and higher reading scores for India. The result for PPVT in particular may highlight the link between early childhood malnutrition and vocabulary development, which starts in early childhood and it is consolidated between ages 3 and 6 years (Jalongo and Sobolak 2011). Math and reading skills, by contrast, are formed later in life when the child is already in school, whereby concurrent investments in nutrition and education, as well the quality of the overall educational environment, could play relatively larger roles as compared to early-life circumstances (Aurino et al. 2019). Fourth, in most cases, the coefficients related to early-life nutrition do not differ by gender. The only exception is the association between HAZ at age 1 year and PPVT, which is higher for girls than for boys in Ethiopia and India, the countries where early childhood nutritional deprivation is more widespread. Despite the extensive literature on the longitudinal associations between early nutrition and childhood cognition, prior evidence on sex-based heterogeneity in these relations is limited as gender inequality has not been a central research question: in fact, most studies either control additively for child gender in the analysis or they do not report on gender heterogeneity. Fifth, when our main model is augmented by some potential channels through which cognitive skills may be developed beyond early-life nutrition, the coefficients on HAZ remain robust. However, the estimates suggest that contemporaneous investments in education (as measured by school enrollment and time spent in educational activities) are more strongly associated with adolescent cognitive attainments, as compared to early nutrition and unpredicted change in nutritional status: being enrolled in formal schooling at age 15 years is always associated with higher learning achievements in each context. Finally, we do not find evidence of gender differences in the relations between schooling and attainments, and the gender findings related to time use and attainments are mixed, depending on the country and the specific indicator of time use considered. However, investments in mid-childhood and adolescent nutrition that are captured by unpredicted and positive HAZ changes favor boys in India and Peru. In augmented models examining changes in nutritional status after age 1-year, unpredicted improvements in HAZ that have occurred by the age of 15 , and some by the age of 8 , tend to benefit boys more than girls across all three cognitive outcomes in India and Peru. For PPVT, these associations offset any initial advantage to girls from their higher age-1-year HAZ in those countries.

The picture of a male advantage in adolescent cognitive development in India and Peru, no gender gaps in Ethiopia, and a pro-female inequality in Vietnam is consistent with previous evidence on gender gaps in educational attainments and investments in these four countries. For instance, Singh and Krutikova (2017) found evidence of pro-boy advantage in vocabulary and math in India, Peru, and Ethiopia, and a pro-female advantage in Vietnam, despite similar starting points between boys and girls at pre-school age. In India, a large literature has documented a wide 
pro-boy advantage in learning achievements (Alcott and Rose 2017; Dercon and Singh 2013; Lopez Boo and Canon 2014) and in accessing private schooling (Sahoo 2017; Woodhead et al. 2013). Lopez Boo and Canon, using only the Indian sample of Young Lives, show steep gender and caste gradients for cognitive development, with upper-caste girls outperforming boys at school entry and later following the general patterns of female disadvantage (already present at 5 years for lower-caste girls) at 8 years, suggesting greater parental investments in education at school age for boys (Lopez Boo and Canon 2014). In Peru, Gertler and Glewwe (1992) found evidence of male advantage in parental willingness to pay for child educational expenditures. However, in the OECD-PISA tests, Peruvian boys tend to perform better in sciences and math, while girls have an advantage in reading. ${ }^{6}$ Ethiopia did tremendous progress in closing the gender gaps in enrolment in primary and secondary schooling, but girls still fall behind boys for tertiary education (Asfaw 2012; Tafere 2017). Data from the Young Lives show gender gaps in school attainments and educational aspirations favoring adolescent girls (Favara 2017). Finally, in Vietnam, adolescent girls perform better in international achievement assessments such as the OECD-PISA in both reading and math ${ }^{7}$ (Azubuike and Little 2019). Using Young Lives school survey data, Azubuike and Little found that Vietnamese girls are generally more motivated and diligent than their peers in their studies and they tend to perform better in both math and reading (Azubuike and Little 2019), while Dang (2007) showed that there are no gender differences in private tuition expenditures.

Further, the gender differences in the associations related to the unpredicted changes in HAZ in India and Peru may reflect unobserved son preferences in health investments that occur during primary school and the early adolescent years, which may be stronger in these two countries as compared to Ethiopia and Vietnam. Recently, Duc has shown that linear growth after 5 years of boys, but not girls, increases disproportionally in face of improvements in the household socioeconomic conditions in India and Peru, but not in Ethiopia or Vietnam (Duc 2019). In the Indian context, there is extensive evidence of son preference in nutritional investments (Jayachandran 2015): boys (and especially first-borns) are breastfed for longer (Jayachandran and Kuziemko 2011), and their dietary quality is generally higher, particularly in adolescence (Aurino 2016). Consistent with this evidence of a proboy bias in the allocation of food and health inputs, using the Young Lives data, Himaz (2018) shows that Indian girls are more likely than boys to become stunted after age 8 years. With regard to Peru, the literature on gender and age differences in the intrahousehold food allocation is much more limited (and in Latin American countries more generally), with mixed findings related to discrimination against girls. Also, existing studies focus on nutritional inputs for very young children, which may be treated differently from school-age children and adolescents (Graham 1997). For Ethiopia and Vietnam, where we did not find evidence of male advantage

\footnotetext{
${ }^{6} \mathrm{http} / /$ gpseducation.oecd.org/CountryProfile?primaryCountry=PER\&treshold=10\&topic=PI (retrieved June 26, 2019).

7 In the case of maths, the difference was not statistically significant, but still in contrast to OECD countries, where boys tend to do better than girls (Azubuike and Little 2019).
} 
when considering post-infancy changes in HAZ, our findings are also consistent with previous literature. Existing evidence from Ethiopia shows that there are no gender disparities in the intrahousehold allocation of nutrients, including after detrimental food security shocks, pointing to overall gender equality (Coates et al. 2018; Tesfay and Abidoye 2019). For Vietnam, the literature is more limited, and mostly focusing on child mortality: for instance, boys have higher child mortality than girls, which it is attributed to higher risky behaviors among boys, rather than to unequitable distribution of nutritional resources (Pham et al. 2013). Indeed, although the country has a tradition of son preference, gender equality policies have been pursued since 1945, likely contributing to bridging, or even reversing, gender gaps in child investments (Azubuike and Little 2019; Pham et al. 2013).

The repeated measures of heights and weights collected in a sample with low attrition over 15 years constitute a unique and important strength of this study. Similarly, the variety of standardized cognitive scores — math, reading, vocabulary — constitute a further asset as it allows examination of skill-based heterogeneity in the associations between early-life HAZ and adolescent learning. Further, data on an extensive set of characteristics over the first 15 years of life in four diverse countries allow us to examine nutritional status at various ages and characterize child development over a broad swath of communities. We also acknowledge several limitations. First, the timing of the measurements of height among adolescents could be problematic, since there is large variation in the timing of puberty. The nutritional data collected at age 8 are before pubertal growth spurts, but data collected at age 15 are after the growth spurts for some of the children and in the middle of the growth spurts for others. Therefore, our estimates using unpredicted change in HAZ to age 15 years include some children who have reached adult height, but others who have not. Without final adult heights, we have an incomplete picture of physical development and its association with cognitive and other outcomes. Further, it is well known that girls reach puberty on average at younger ages than boys and are thus more likely to have reached adult height by age 15 years. Since timing of puberty is partially idiosyncratic, some unpredicted improvements in HAZ will be due to the timing of puberty, rather than a true increase in longer-run adult HAZ compared to the reference population. If this is more likely for girls than boys, we might be underestimating gender disparities in the associations between unpredicted growth and cognitive outcomes. However, our examination of the "early puberty" channel for cognitive skills suggests that early puberty is only predictive for math, and does not differ by gender, except for reading test scores for Peru, which show evidence of a positive association for girls. Thus, we do not expect this possible bias to have a large influence on our estimates. Second, the PPVT vocabulary tests are standardized within languages, but they do not permit comparisons across languages. This is a limitation of the current stage of development of such tests more than a limitation of the study per se, but it does constrain our approach to their analysis in our study.

Despite the caveats due to such limitations, the strengths of this study remain considerable. We contribute to understanding of the associations of early-life nutrition with cognitive skills beyond early and late childhood (the focus of most previous literature) into adolescence. We therefore provide important evidence that early-life $\mathrm{HAZ}$ is associated with learning trajectories, but also how these trajectories might 
be altered along the way through later investments in schooling and nutrition. We show that some nutritional gains in adolescence were not predicted based on earlylife nutrition, but rather on changes post-infancy. From this analysis, we pinpoint gender differences in the contribution of post-infancy growth and the development of adolescent cognitive skills, suggesting that investments in boys may differ from girls throughout childhood and adolescence due to multiple reasons, including gendered parental preferences and societal norms, expectations about roles within and outside the household, early marriage, fertility and childcare, and expected returns to schooling. Therefore, for adolescent cognitive development, what is important is not only conditions into the first year of life, but also later investments in education and health. Gender disparities in these investments after the first 1,000 days may thus contribute to differential cognitive outcomes in mid-adolescence between boys and girls in some contexts where son-bias may be pronounced.

Under the assumption that the associations that we present are related in part to causal relations, finally, there are possibly some important policy implications of our results. First, in terms of adolescent skills, our evidence re-iterates the crucial importance of investments in early-life nutrition. However, we show that investments in post-infancy food security and nutrition are also important for the development of adolescent skills. Finally, given that the underlying attitudes to gender equality may vary across countries and at different stages of childhood in some critical respects, effective policies should be tailored to individual contexts and stages of childhood development.

Acknowledgements The authors wish to thank the Young Lives teams in Oxford and in the study countries for granting early access to the 2016 data for Round 5. Young Lives is an international study of childhood poverty conducted in Ethiopia, India, Peru, and Vietnam over 15 years (www.younglives.org. uk). Young Lives is core-funded by UK aid from the Department for International Development (DFID) and was co-funded from 2010-2014 by the Netherlands Ministry of Foreign Affairs and from 2014 to 2015 by Irish Aid. We also wish to thank Florencia Torche and Jenna Nobles for very useful comments on an earlier draft and two anonymous peer reviewers for their feedback. Elisabetta Aurino acknowledges the Imperial College Research Fellowship. Mary Penny received funding from the Old Dart Foundation. Finally, we thank the Young Lives study children and their families for sharing their time and insights, without which this study would not be possible.

Author contributions EA conducted data analysis and contributed to conceptualization, data interpretation, report writing, and revision. WS and JB contributed to conceptualization, data interpretation, report writing, and revision. MP contributed to project management, conceptualization, data interpretation, and revision. All authors approved the final article.

Open Access This article is distributed under the terms of the Creative Commons Attribution 4.0 International License (http://creativecommons.org/licenses/by/4.0/), which permits unrestricted use, distribution, and reproduction in any medium, provided you give appropriate credit to the original author(s) and the source, provide a link to the Creative Commons license, and indicate if changes were made. 


\section{References}

Adair, L. S., Fall, C. H., Osmond, C., Stein, A. D., Martorell, R., Ramirez-Zea, M., ... Victora, C. G. (2013). Associations of linear growth and relative weight gain during early life with adult health and human capital in countries of low and middle income: findings from five birth cohort studies. The Lancet, 382(9891), 525-534. https://doi.org/10.1016/S0140-6736(13)60103-8.

Akresh, R., Bhalotra, S., Leone, M., \& Osili, U. (2017). First and Second Generation Impacts of the Biafran War. Retrieved from www.iza.org.

Alcott, B., \& Rose, P. (2017). Learning in India's primary schools: How do disparities widen across the grades? International Journal of Educational Development, 56, 42-51. https://doi.org/10.1016/j. ijedudev.2017.05.002.

Alderman, H., Hoddinott, J., \& Kinsey, B. (2006). Long term consequences of early childhood malnutrition. Oxford Economic Papers, 58(3), 450-474. Retrieved from http://oep.oxfordjournals.org/conte $\mathrm{nt} / 58 / 3 / 450$.abstract

Alderman, H., \& King, E. M. (1998). Gender differences in parental investment in education. Structural Change and Economic Dynamics, 9(4), 453-468. https://doi.org/10.1016/S0954-349X(98)00040-X.

Almond, D., \& Currie, J. (2011). Killing me softly: The fetal origins hypothesis. Journal of Economic Perspectives, 25(3), 153-172. https://doi.org/10.1257/jep.25.3.153.

Asfaw, A. (2012). Gender Inequalities in Tertiary Education in Ethiopia (Global Scholars Program Working Papers). Washington, D. C. Retrieved from https://www.brookings.edu/wp-content/uploa ds/2018/03/gender-inequalities-in-tertiary-education-in-ethiopia.pdf.

Aurino, E. (2016). Do boys eat better than girls in India? Longitudinal evidence on dietary diversity and food consumption disparities among children and adolescents. Economics and Human Biology. https://doi.org/10.1016/j.ehb.2016.10.007.

Aurino, E., \& Burchi, F. (2017). Children's multidimensional health and medium-term cognitive skills in low- and middle-income countries. European Journal of Development Research, 29(2), 289-311. https://doi.org/10.1057/ejdr.2016.7.

Aurino, E., Fledderjohann, J., \& Vellakkal, S. (2019). Inequalities in adolescent learning: Does the timing and persistence of food insecurity at home matter? Economics of Education Review, 70, 94-108. https://doi.org/10.1016/J.ECONEDUREV.2019.03.003.

Azubuike, O. B., \& Little, A. W. (2019). Learning Motivations, Learning Outcomes and Gender in Vietnam (Working paper series No. 181). Oxford.

Backstrand, J. R., Allen, L. H., Pelto, G. H., \& Chávez, A. (1997). Examining the gender gap in nutrition: An example from rural Mexico. Social Science and Medicine, 44(11), 1751-1759. https://doi. org/10.1016/S0277-9536(96)00376-0.

Barnett, I., Ariana, P., Petrou, S., Penny, M. E., Duc, L. T., Galab, S., .. Boyden, J. (2013). Cohort Profile: The Young Lives Study. International Journal of Epidemiology, 42(3), 701-708. https://doi. org/10.1093/ije/dys082.

Behrman, J. R. (1988). Intrahousehold allocation of nutrients in rural India: Are boys favored? Do parents exhibit inequality aversion? Oxford Economic Papers. https://doi.org/10.1093/oxfordjournals.oep. a041845.

Behrman, J. R., \& Rosenzweig, M. R. (2004). Returns to birthweight. Review of Economics and Statistics, 86(2), 586-601.

Black, M. M., Walker, S. P., Fernald, L. C. H., Andersen, C. T., DiGirolamo, A. M., Lu, C., ... Shiffman, J. (2017). Early childhood development coming of age: science through the life course. The Lancet, 389(10064), 77-90.

Bundy, D. A. P., de Silva, N., Horton, S., Patton, G. C., Schultz, L., Jamison, D. T., ... Appleby, L. (2017). Investment in child and adolescent health and development: key messages from Disease Control Priorities, 3rd Edition. The Lancet, 2423-2478. https://doi.org/10.1016/S0140-6736(17)32417-0.

Cheung, Y. B., \& Ashorn, P. (2010). Continuation of linear growth failure and its association with cognitive ability are not dependent on initial length-for-age: A longitudinal study from 6 months to 11 years of age. Acta Paediatrica, International Journal of Paediatrics, 99(11), 1719-1723. https:// doi.org/10.1111/j.1651-2227.2009.01593.x.

Coates, J., Patenaude, B. N., Rogers, B. L., Roba, A. C., Woldetensay, Y. K., Tilahun, A. F., et al. (2018). Intra-household nutrient inequity in rural Ethiopia. Food Policy. https://doi.org/10.1016/j.foodp ol.2018.10.006. 
Crookston, B. T., Penny, M. E., Alder, S. C., Dickerson, T. T., Merrill, R. M., Stanford, J. B., ... Dearden, K. A. (2010). Children Who Recover from Early Stunting and Children Who Are Not Stunted Demonstrate Similar Levels of Cognition. Journal of Nutrition, 140(11), 1996-2001. https://doi. org/10.3945/jn.109.118927.

Crookston, B. T., Schott, W., Cueto, S., Dearden, K. A., Engle, P., Georgiadis, A., ... Behrman, J. R. (2013). Postinfancy growth, schooling, and cognitive achievement: Young lives 1-4. American Journal of Clinical Nutrition, 98(6), 1555-1563. https://doi.org/10.3945/ajen.113.067561.

Cueto, S., Leon, J., Guerrero, G., \& Muñoz, I. (2009). Psychometric characteristics of cognitive development and achievement instruments in Round 2 of Young Lives. Young Lives Technical Note (Vol. 15). Retrieved from http://grade.org.pe/upload/publicaciones/archivo/download/pubs/NDMtn25.pdf.

Dahl, R. E., Allen, N. B., Wilbrecht, L., \& Suleiman, A. B. (2018). Importance of investing in adolescence from a developmental science perspective. Nature, 554(7693), 441-450. https://doi. org/10.1038/nature25770.

Dang, H. A. (2007). The determinants and impact of private tutoring classes in Vietnam. Economics of Education Review, 26(6), 683-698. https://doi.org/10.1016/j.econedurev.2007.10.003.

De Onis, M., Garza, C., Victora, C. G., Onyango, A. W., Frongillo, E. A., \& Martines, J. (2004). The WHO Multicentre Growth Reference Study: Planning, study design, and methodology. Food and Nutrition Bulletin, 25(1_suppl1), S15-S26.

de Onis, M., et al. (2007). Development of a WHO growth reference for school-aged children and adolescents children and adolescents. Bulletin of the World Health Organization, 85(9), 649-732. https:// doi.org/10.2471/BLT.07.043497.

Dercon, S., \& Singh, A. (2013). From nutrition to aspirations and self-efficacy: Gender bias over time among children in four countries. World Development, 45, 31-50. https://doi.org/10.1016/j.world dev.2012.12.001.

Duc, L. T. (2019). Household wealth and gender gap widening in height: Evidence from adolescents in Ethiopia, India, Peru, and Vietnam. Economics \& Human Biology. https://doi.org/10.1016/J. EHB.2019.05.008.

Duc, L. T., \& Behrman, J. R. (2017). Heterogeneity in predictive power of early childhood nutritional indicators for mid-childhood outcomes: Evidence from Vietnam. Economics \& Human Biology, 26, 86-95. https://doi.org/10.1016/j.ehb.2017.02.002.

Favara, M. (2017). Do dreams come true? Aspirations and educational attainments of ethiopian boys and girls. Journal of African Economies, 26(5), 561-583. https://doi.org/10.1093/jae/ejx018.

Fink, G., \& Rockers, P. C. (2014). Childhood growth, schooling, and cognitive development: Further evidence from the Young Lives study. American Journal of Clinical Nutrition, 100(1), 182-188. https ://doi.org/10.3945/ajcn.113.080960.

Friedmann, N., \& Rusou, D. (2015). Critical period for first language: the crucial role of language input during the first year of life. Current Opinion in Neurobiology, 35, 27-34.

Fuhrmann, D., Knoll, L. J., \& Blakemore, S.-J. (2015). Adolescence as a sensitive period of brain development. Trends in Cognitive Sciences, 19(10), 558-566.

Gale, C. R., O’Callaghan, F. J., Godfrey, K. M., Law, C. M., \& Martyn, C. N. (2004). Critical periods of brain growth and cognitive function in children. Brain, 127(2), 321-329.

Gandhi, M., Ashorn, P., Maleta, K., Teivaanmäki, T., Duan, X., \& Cheung, Y. B. (2011). Height gain during early childhood is an important predictor of schooling and mathematics ability outcomes. Acta Paediatrica, 100(8), 1113-1118. https://doi.org/10.1111/j.1651-2227.2011.02254.x.

Georgiadis, A., Benny, L., Crookston, B. T., Duc, L. T., Hermida, P., Mani, S., ... Behrman, J. R. (2016). Growth trajectories from conception through middle childhood and cognitive achievement at age 8 years: Evidence from four low- and middle-income countries. SSM - Population Health, 2, 43-54. https://doi.org/10.1016/j.ssmph.2016.01.003.

Gittelsohn, J. (1991). Opening the box: Intrahousehold food allocation in rural Nepal. Social Science and Medicine, 33(10), 1141-1154. https://doi.org/10.1016/0277-9536(91)90230-A.

Glewwe, P., \& King, E. M. (2001). The impact of early childhood nutritional status on cognitive development: Does the timing of malnutrition matter? World Bank Economic Review, 15(1), 81-113. https ://doi.org/10.1093/wber/15.1.81.

Graham, M. A. (1997). Food allocation in rural Peruvian households: Concepts and behavior regarding children. Social Science and Medicine, 44(11), 1697-1709. https://doi.org/10.1016/S0277 -9536(96)00372-3. 
Hadley, C., Lindstrom, D., Tessema, F., \& Belachew, T. (2008). Gender bias in the food insecurity experience of Ethiopian adolescents. Social Science and Medicine, 66(2), 427-438. https://doi. org/10.1016/j.socscimed.2007.08.025.

Himaz, R. (2018). Stunting later in childhood and outcomes as a young adult: Evidence from India. World Development, 104, 344-357. https://doi.org/10.1016/j.worlddev.2017.12.019.

Hoddinott, J., Behrman, J. R., Maluccio, J. A., Melgar, P., Quisumbing, A. R., Ramirez-Zea, M., ... Martorell, R. (2013). Adult consequences of growth failure in early childhood. The American Journal of Clinical Nutrition, 98(5), 1170-1178.

Jalongo, M. R., \& Sobolak, M. J. (2011). Supporting young children's vocabulary growth: The challenges, the benefits, and evidence-based strategies. Early Childhood Education Journal, 38(6), 421429. https://doi.org/10.1007/s10643-010-0433-X.

Jayachandran, S. (2015). The roots of gender inequality in developing countries. Annual Review of Economics, 7(1), 63-88. https://doi.org/10.1146/annurev-economics-080614-115404.

Jayachandran, S., \& Kuziemko, I. (2011). Why domothers breastfeed girls less than boys? Evidence and implications forchild health in india. Quarterly Journal of Economics, 126(3), 1485-1538. https:// doi.org/10.1093/qje/qjr029.

Kowalski, A. J., Georgiadis, A., Behrman, J. R., Crookston, B. T., Fernald, L. C. H., \& Stein, A. D. (2018). Linear growth through 12 years is weakly but consistently associated with language and math achievement scores at age 12 years in 4 low- or middle-income countries. Journal of Nutrition, 148(11), 1852-1859. https://doi.org/10.1093/jn/nxy191.

Kraemer, S. (2000). The fragile male. British Medical Journal, 321, 1609-1612. Retrieved from https:// www.ncbi.nlm.nih.gov/pmc/articles/PMC1119278/pdf/1609.pdf

Kuhl, P. K. (2010). Brain mechanisms in early language acquisition. Neuron, 67(5), 713-727.

Le Pham, T., Kooreman, P., Koning, R. H., \& Wiersma, D. (2013). Gender patterns in Vietnam's child mortality. Journal of Population Economics, 26(1), 303-322. https://doi.org/10.1007/s0014 8-012-0425-9.

Leroy, J. L., Ruel, M., Habicht, J.-P., \& Frongillo, E. A. (2015). Using height-for-age differences (HAD) instead of height-for-age z-scores (HAZ) for the meaningful measurement of population-level catchup in linear growth in children less than 5 years of age. BMC Pediatrics, 15(1), 145.

Lopez Boo, F., \& Canon, M. E. (2014). Reversal of gender gaps in child development: Evidence from young children in India. Economics Letters, 124(1), 55-59. https://doi.org/10.1016/j.econl et.2014.04.021.

Lundeen, E. A., Behrman, J. R., Crookston, B. T., Dearden, K. A., Engle, P., Georgiadis, A., ... Stein, A. D. (2014). Growth faltering and recovery in children aged 1-8 years in four low-and middle-income countries: Young Lives. Public Health Nutrition, 17(9), 2131-2137.

Maluccio, J. A., Hoddinott, J., Behrman, J. R., Martorell, R., Quisumbing, A. R., \& Stein, A. D. (2009). The impact of improving nutrition during early childhood on education among Guatemalan adults. The Economic Journal, 119(537), 734-763.

Marcoux, A. (2002). Sex differentials in undernutrition: A look at survey evidence. Population and Development Review, 28(2), 275-284. https://doi.org/10.1111/j.1728-4457.2002.00275.x.

Martorell, R., Horta, B. L., Adair, L. S., Stein, A. D., Richter, L., Fall, C. H. D., ... Consortium on Health Orientated Research in Transitional Societies Group, C. on H. O. R. in T. S. (2010). Weight gain in the first two years of life is an important predictor of schooling outcomes in pooled analyses from five birth cohorts from low- and middle-income countries. The Journal of Nutrition, 140(2), 348-354. https://doi.org/10.3945/jn.109.112300.

Morrow, V. (2013). Practical ethics in social research with children and families in young lives: A longitudinal study of childhood poverty in Ethiopia, Andhra Pradesh (India), Peru and Vietnam. Methodological Innovations Online. https://doi.org/10.4256/mio.2013.011.

Nandi, A., Behrman, J. R., Kinra, S., \& Laxminarayan, R. (2018). Early-life nutrition is associated positively with schooling and labor market outcomes and negatively with marriage rates at age 20-25 years: Evidence from the Andhra Pradesh Children and Parents Study (APCAPS) in India. The Journal of Nutrition, 148(1), 140-146.

Patton, G. C., Sawyer, S. M., Santelli, J. S., Ross, D. A., Afifi, R., Allen, N. B., ... Viner, R. M. (2016). Our future: A Lancet commission on adolescent health and wellbeing. Lancet (London, England), 387(10036), 2423-2478. https://doi.org/10.1016/S0140-6736(16)00579-1.

Reynolds, S. A., Andersen, C., Behrman, J., Singh, A., Stein, A. D., Benny, L., ... Georgiadis, A. (2017). Disparities in children's vocabulary and height in relation to household wealth and parental 
schooling: A longitudinal study in four low-and middle-income countries. SSM-Population Health, 3, 767-786.

Rubio-Codina, M., Attanasio, O., Meghir, C., Varela, N., \& Grantham-McGregor, S. (2015). The socioeconomic gradient of child development: Cross-sectional evidence from children 6-42 months in Bogota. Journal of Human Resources, 50(2), 464-483.

Saewyc, E. R. (2017). A global perspective on gender roles and identity. Journal of Adolescent Health, 61, S1-S2. https://doi.org/10.1016/j.jadohealth.2017.07.010.

Sahoo, S. (2017). Intra-household gender disparity in school choice: Evidence from private schooling in India. Journal of Development Studies, 53(10), 1714-1730. https://doi.org/10.1080/00220 388.2016.1265943.

Schott, W. B., Aurino, E., Penny, M. E., \& Behrman, J. R. (2017). Adolescent mothers' anthropometrics and grandmothers' schooling predict infant anthropometrics in Ethiopia, India, Peru, and Vietnam. Annals of the New York Academy of Sciences. https://doi.org/10.1111/nyas.13455.

Schott, W. B., Crookston, B. T., Lundeen, E. A., Stein, A. D., \& Behrman, J. R. (2013). Periods of child growth up to age 8 years in Ethiopia, India, Peru and Vietnam: Key distal household and community factors. Social Science and Medicine, 97, 278-287. https://doi.org/10.1016/j.socsc imed.2013.05.016.

Singh, A., \& Krutikova, S. (2017). Starting together, growing apart: Gender gaps in learning from preschool to adulthood in four developing countries (Working Paper Series No. 174). Oxford. Retrieved from https://www.younglives.org.uk/sites/www.younglives.org.uk/files/YL-WP174-Singh.pdf.

Steinberg, L. (2014). Age of opportunity: Lessons from the new science of adolescence. Boston: Houghton Mifflin Harcourt.

Sudfeld, C. R., McCoy, D. C., Danaei, G., Fink, G., Ezzati, M., Andrews, K. G., et al. (2015). Linear growth and child development in low-and middle-income countries: A meta-analysis. Pediatrics, 135(5), e1266-e1275.

Tafere, Y. (2017). Educational trajectories from childhood to early adulthood: Aspirations, gender and poverty in Ethiopia (working papers No. 171). Oxford.

Tesfay, G. B., \& Abidoye, B. (2019). Shocks in food availability and intra-household resources allocation: Evidence on children nutrition outcomes in Ethiopia. Agricultural and Food Economics, 7(1), 3. https://doi.org/10.1186/s40100-019-0120-1.

Torche, F., \& Conley, D. (2015). A pound of flesh. The use of birthweight as a measure of human capital endowment in economics research. In J. Komlos \& I. R. Kelly (Eds.), The Oxford handbook of economics and human biology (Vol. 1). Oxford: Oxford University Press. https://doi.org/10.1093/oxfor dhb/9780199389292.013.26.

Torche, F., \& Echevarría, G. (2011). The effect of birthweight on childhood cognitive development in a middle-income country. International Journal of Epidemiology, 40(4), 1008-1018. https://doi. org/10.1093/ije/dyr030.

Van den Berg, G. J., Lundborg, P., Nystedt, P., \& Rooth, D.-O. (2014). Critical periods during childhood and adolescence. Journal of the European Economic Association, 12(6), 1521-1557.

van den Berg, G. J., Pinger, P. R., \& Schoch, J. (2016). Instrumental variable estimation of the causal effect of hunger early in life on health later in life. Economic Journal. https://doi.org/10.1111/ ecoj. 12250.

Victora, C. G., Adair, L., Fall, C., Hallal, P. C., Martorell, R., Richter, L., et al. (2008). Maternal and child undernutrition: consequences for adult health and human capital. The Lancet. Elsevier. https://doi. org/10.1016/S0140-6736(07)61692-4.

Victora, Cesar Gomes, de Onis, M., Hallal, P. C., Blössner, M., \& Shrimpton, R. (2010). Worldwide timing of growth faltering: Revisiting implications for interventions. Pediatrics, 125(3), e473-e480. https://doi.org/10.1542/peds.2009-1519.

Viner, R. M., Ozer, E. M., Denny, S., Marmot, M., Resnick, M., Fatusi, A., et al. (2012). Adolescence and the social determinants of health. The Lancet, 379(9826), 1641-1652. https://doi.org/10.1016/s0140 $-6736(12) 60149-4$.

Viner, R. M., Ross, D., Hardy, R., Kuh, D., Power, C., Johnson, A., ... Kelly, Y. (2015). Life course epidemiology: recognising the importance of adolescence. BMJ Publishing Group Ltd.

Vlassoff, C. (2007). Gender differences in determinants and consequences of health and illness. Journal of Health, Population and Nutrition, 25(1), 47-61. Retrieved from http://www.ncbi.nlm.nih.gov/ pubmed/17615903.

White, I. R., Royston, P., \& Wood, A. M. (2011). Multiple imputation using chained equations: Issues and guidance for practice. Statistics in Medicine, 30(4), 377-399. https://doi.org/10.1002/sim.4067. 
Woodhead, M., Frost, M., \& James, Z. (2013). Does growth in private schooling contribute to Education for All? Evidence from a longitudinal, two cohort study in Andhra Pradesh, India. International Journal of Educational Development, 33(1), 65-73. https://doi.org/10.1016/j.ijedudev.2012.02.005.

World Bank. (2018). Learning to realize education's promise. World Development Report. https://doi. org/10.1016/S0305-750X(98)90001-8.

Publisher's Note Springer Nature remains neutral with regard to jurisdictional claims in published maps and institutional affiliations.

\section{Affiliations}

\section{Elisabetta Aurino ${ }^{1,5} \cdot$ Whitney Schott ${ }^{2}$. Jere R. Behrman ${ }^{2,3} \cdot$ Mary Penny $^{4}$}

Whitney Schott

wschott@pop.upenn.edu

Jere R. Behrman

jbehrman@econ.upenn.edu

Mary Penny

mpenny@iin.sld.pe

1 Department of Economics and Public Policy, Imperial College London, London, UK

2 Population Studies Center, University of Pennsylvania, 3718 Locust Walk, Philadelphia, PA 19104, USA

3 Department of Economics, University of Pennsylvania, 133 South 36th Street, Philadelphia, PA 19104-6297, USA

4 Instituto de Investigación Nutricional, Molina 1885 La Molina Ex Av. La, Av. La Universidad 685, La Molina, Peru

5 Young Lives, University of Oxford, Oxford, UK 